\title{
Synaptic Responses to Whisker Deflections in Rat Barrel Cortex as a Function of Cortical Layer and Stimulus Intensity
}

\author{
W. Bryan Wilent and Diego Contreras \\ Department of Neuroscience, University of Pennsylvania School of Medicine, Philadelphia, Pennsylvania 19106-6074
}

To study the synaptic and spike responses of barrel cortex neurons as a function of cortical layer and stimulus intensity, we recorded intracellularly in vivo from barbiturate anesthetized rats while increasing the velocity-acceleration of the whisker deflection. Granular (Gr; layer 4) cells had the EPSP with the shortest peak and onset latency, whereas supragranular (SGr; layers 2-3) cells had the EPSP with longest duration and slowest rate of rise. Infragranular (Igr; layers 5-6) cells had intermediate values, and thus each layer was unique. The spike response peak of Gr cells was followed by IGr and then by SGr cells. In all cells, depolarization reduced the duration and amplitude of the response, but only in Gr cells did it reveal an early IPSP that cut short the EPSP. This early IPSP was associated with a large decrease in input resistance and an apparent reversal potential below spike threshold; consequently, synaptic integration in $\mathrm{Gr}$ cells was limited to the initial 5-7 msec of the response. In contrast, in SGr and IGr cells, results suggest an overlap in time of the EPSP and IPSP, with a small drop in input resistance and an apparent reversal potential above spike threshold, facilitating input integration for up to 20 msec. Decreasing stimulus intensity (velocity-acceleration) reduced the amplitude and increased the peak latency of the response without altering its synaptic composition. We propose that layer 4 circuits are better suited to perform coincidence detection, whereas supra and infragranular circuits are better designed for input integration.

Key words: barrel; cortex; EPSP; inhibition; intracellular; IPSP; synaptic; velocity; whisker; in vivo; integration; acceleration

\section{Introduction}

A successful strategy to investigate how information is represented in the nervous system is to vary specific parameters of a sensory stimulus, for which the system under study is selective, while measuring the neuronal response from the corresponding area of the sensory cortex. Such a strategy has generated the basic framework of our understanding of how sensory cortices represent specific aspects of sensory inputs (Mountcastle, 1957; Hubel and Wiesel, 1962; Simons, 1978).

In the rodent barrel system, neurons are exquisitely sensitive to velocity (Gibson and Welker, 1983; Ito, 1985; Shoykhet et al., 2000; Deschenes et al., 2003; Temereanca and Simons, 2003; Lee and Simons, 2004) and acceleration (Temereanca and Simons, 2003) at which the corresponding principal whisker in the mystacial pad is deflected. As rodents explore, their whiskers repetitively move back and forth at 5-15 Hz (Welker et al., 1964; Carvell and Simons, 1995; Berg and Kleinfeld, 2003) contacting surfaces and objects, causing small angular deflections at the base of the whiskers. Encoding deflection velocity-acceleration is probably critical for discriminating between surfaces of different textures (Dykes, 1975; Temereanca and Simons, 2003), a task that

Received 0ct. 8, 2003; revised Feb. 15, 2004; accepted March 9, 2004.

This work was sponsored by The Human Frontier Science Program Organization. We thank Gene Civillico, Michael Higley, Larry Palmer, Feraz Rahman, Ashlan Reid, and Noah Roy for helpful comments in preparation of this manuscript. We also thank Dan Simons for his assistance in fabricating the whisker stimulators and the two anonymous reviewers for their thorough and helpful comments.

Correspondence should be addressed to Diego Contreras, Department of Neuroscience, University of Pennsylvania School of Medicine, 215 Stemmler Hall, Philadelphia, PA 19106-6074. E-mail: diego@@mail.med.upenn.edu. DOI:10.1523/JNEUROSCI.5782-03.2004

Copyright $\odot 2004$ Society for Neuroscience $\quad$ 0270-6474/04/243985-14\$15.00/0 rats are capable of performing (Guic-Robles et al., 1989; Carvell and Simons, 1990). It may also be critical for determining the distance to objects (Cowan et al., 2004), because striking a whisker at different distances from the face generates deflections with different angular velocities.

Velocity is first encoded by both rapidly and slowly adapting trigeminal ganglion neurons (Welker et al., 1964; Lichtenstein et al., 1990; Shoykhet et al., 2000). In the ventrobasal (VB) nucleus of the thalamus, increasing the velocity of whisker deflection increases the initial firing rate without a change in the total output (Pinto et al., 2000). In contrast, in layer 4 of the barrel cortex, extracellular studies have shown that increasing velocity increases response magnitude (Pinto et al., 2000). In addition, the layer 4 circuit is more sensitive to the initial frequency of thalamic input rather than its total number of spikes. In that study and in modeling work (Pinto et al., 1996, 2003), it was proposed that the transformation in stimulus representation strategy, from one on the basis of the timing of the response (in VB) to one on the basis of the magnitude (in the barrel, layer 4), is attributable to the properties of local inhibition in layer 4 . Here, we describe by means of intracellular recordings in vivo the synaptic and spike responses of barrel cortex neurons to the deflection of the principal whisker as a function of stimulus intensity, which in this study is equivalent to the velocity-acceleration of the deflection. We show that in layer 4, inhibition dominates the synaptic response after the first 6-7 msec to all stimulus intensities, thereby leaving only a small window at the beginning of the response for the integration of excitatory inputs. In contrast, in supragranular (SGr) layers 2-3 and infragranular (IGr) layers 5-6, inhibition is 
less powerful and overlaps with excitation for most of the response, leaving a much longer time window for input integration.

\section{Materials and Methods}

Surgery and preparation. Experiments were conducted in accordance with the ethical guidelines of the National Institutes of Health and with the approval of the University of Pennsylvania Institutional Animal Care and Use Committee. Adult male Sprague Dawley rats (350-450 gm) were anesthetized with pentobarbital $(50 \mathrm{mg} / \mathrm{kg}$, i.p.). Buprenorphine $(0.03 \mathrm{mg} / \mathrm{kg}$, s.c. $)$ was administered to provide additional analgesia. Animals were paralyzed with gallamine triethiodide and artificially ventilated. End-tidal $\mathrm{CO}_{2}(3.5-3.7 \%)$ and heart rate were continuously monitored. Body temperature was maintained at $37^{\circ} \mathrm{C}$ via servo-controlled heating blanket and rectal thermometer (Harvard Apparatus, Holliston, MA). The depth of anesthesia was maintained by supplemental doses of the same anesthetic to keep a constant heart rate and a constant highamplitude, low-frequency electroencephalogram (EEG) as recorded from a bipolar electrode inserted into the cortex.

For cortical intracellular recordings, the animal was placed in a stereotaxic apparatus (David Kopf Instruments, Tujunga, CA), and a craniotomy was made to expose the surface of the barrel cortex $(1.0-3.0 \mathrm{~mm}$ posterior to bregma; $4.0-7.0 \mathrm{~mm}$ lateral to the midline). The dura was resected over the recording area, and mineral oil was applied to prevent desiccation. The stability of recordings was improved by drainage of the cisterna magna, hip suspension, and filling of the holes made for recording with a solution of $4 \%$ agar.

Electrophysiological recordings. Intracellular recordings were performed with glass micropipettes filled with $3 \mathrm{~m}$ potassium acetate and DC resistances of 80-90 M $\Omega$. The intracellular recordings were usually obtained within $1 \mathrm{~mm}$ of the EEG recording electrode. Pipettes were oriented normal to the cortical surface, and the vertical depth was read on the scale of the micromanipulator. This reading was $<40 \mu \mathrm{m}$ apart from the position of neurons filled with neurobiotin $(n=15)$ (see Fig. 1). A high-impedance amplifier (bandpass, $0-5 \mathrm{kHz}$ ) with active bridge circuitry (Cygnus Technology, Delaware Water Gap, PA) was used to record and inject current into the cells. Data was digitized at $10 \mathrm{kHz}$ and stored on a Nicolet Vision (Nicolet Instrument Technologies, Madison, WI). A computer operating Labview (National Instruments, Austin, TX) was used for the on-line averaging of responses. Data was subsequently transferred to another computer for off-line analysis.

Whisker stimulation. Before recording, whiskers were trimmed to a length of $\sim 12 \mathrm{~mm}$. Individual whiskers were mechanically deflected using ceramic piezoelectric bimorphs (custom made; Piezo Systems, Cambridge, MA) constructed according to Simons (1983) with some minor variations. The two bimorphs of stage 1 were $30 \mathrm{~mm}$ long and $7 \mathrm{~mm}$ wide, and the two bimorphs of stage 2 were $30 \mathrm{~mm}$ long and $3 \mathrm{~mm}$ wide. Instead of a hollow piece of dried grass extending from the bimorphs, we used a glass micropipette ( 1.0 outer diameter; 0.78 inner diameter) that extended $20 \mathrm{~mm}$ from the end of stage 2. It was glued to the bimorph with an epoxy cement and electrically isolated from the bimorph with a thin piece of plastic. The pipette glass was pulled and the tip shaped so that the opening was small enough to ensure a snug encasing of the last $2-3 \mathrm{~mm}$ of the trimmed whisker. The device was mounted on a Narishige (Tokyo, Japan) micromanipulator and positioned on a whisker with the aid of a surgical microscope. The bimorphs were controlled with Labview and a National Instruments analog out board. Instead of applying a fourthorder Bessel filter, as in Simons (1983), to round the corners of the driving waveform, we used a low-pass Butterworth filter with numerator and denominator coefficients of orders 4 and 1, respectively, and a cutoff frequency of $100 \mathrm{~Hz}$. After filtering, deflection amplitudes and velocities were calibrated with a fast CCD camera (frame rate, $0.7 / \mathrm{msec}$ ). Residual mechanical ringing of the stimulator was dependent on deflection velocity and was $\sim 10 \mu \mathrm{m}$ for the maximum velocity with a resonance frequency of $200 \mathrm{~Hz}$ (period of $5 \mathrm{msec}$ ). In addition, a postanalyses reassessment of stimulator calibration showed that the onset of the ringing occurred after the peak of the membrane potential $(\mathrm{Vm})$ response exhibited by granular $(\mathrm{Gr})$ cells lending additional confidence that our results were not contaminated by mechanical ringing. For esthetic purposes, the stimulus traces shown in the figures are the untransformed trapezoidal waveforms. Once a stable recording was obtained, a whisker was then repeatedly deflected in eight randomly interleaved directions from 0 to $315^{\circ}$ in $45^{\circ}$ increments. Given the extensive subthreshold receptive fields of barrel cortex neurons (Moore and Nelson, 1998; Zhu and Connors, 1999; Brecht and Sakmann, 2002; Brecht et al., 2003; Higley and Contreras, 2003), a minimum of six whiskers was tested for each cell, and the whisker that evoked the most spikes was deemed the principal whisker (PW). However, suprathreshold responses could not be evoked from all cells at rest. Therefore, in cells exhibiting exclusively subthreshold responses, the whisker that evoked the largest depolarizing response from resting membrane potential was deemed the PW. Comparable with PW determination, the preferred direction (PD) was defined as the direction that evoked the most spikes or the largest depolarizing response.

To assess how deflection velocity-acceleration affects the response, the PW was then repeatedly deflected in the PD using five randomly interleaved onset-offset velocities $\left(160,350,650,1000\right.$, and $\left.1300^{\circ} / \mathrm{sec}\right)$. The values used here were chosen on the basis of measurements from naturally whisking rats (Carvell and Simons, 1990; Bermejo et al., 1998) All stimuli were $100 \mathrm{msec}$ ramp and hold deflections delivered at $\leq 0.5 \mathrm{~Hz}$ to prevent steady-state adaptation of whisker-evoked responses (Moore et al., 1999). Because of the smoothing of the ramps driving the piezos, the velocity of the deflection was not constant. The angular velocities we report here are the peak velocities reached during the deflection. The smoothing also causes the velocity to slowly asymptote, but $90 \%$ of the peak velocity is attained within $4.4 \mathrm{msec}$ of stimulus onset. The angular velocity depends critically on the distance of the stimulator to the face. We were extremely careful in positioning the tip of the holding glass at 10 $\mathrm{mm}$ from the face, but even a $1 \mathrm{~mm}$ error can greatly affect the angular velocity and acceleration. Importantly, the distance from the face was consistent for any given battery of tests on a given whisker. These measurements of angular displacement also assume a rigid whisker that only pivots at the base, which may slightly vary from whisker to whisker. These values of velocity should therefore be considered as close approximations. As best as we could resolve with our camera, the movement of the stimulator mimicked the driving waveform, and the peak velocity of the stimulus movement was the same as the theoretical value obtained from the waveform of the driving voltage. Given the limitations in our method of calibration, which has a spatial resolution of $10 \mu \mathrm{m}$ and a temporal resolution of $0.7 \mathrm{msec}$, we could not accurately assess the peak or the rate of change of acceleration of the stimulator in the first $1.5 \mathrm{msec}$ of the movement, which is when most of the acceleration occurs. The theoretical value of acceleration, derived from the waveform of the voltage driving the bimorphs did increase linearly with velocity. The theoretical average values for acceleration in the first $1.5 \mathrm{msec}$ of deflection are $0.9 \times$ $10^{5 \circ} / \mathrm{sec}^{2}$ (for $160^{\circ} / \mathrm{sec}$ ), $2.1 \times 10^{5 \%} / \mathrm{sec}^{2}$ (for $350 \% \mathrm{sec}$ ), $3.8 \times 10^{5 \%} / \mathrm{sec}^{2}$ (for $650 \% \mathrm{sec}$ ), $6.0 \times 10^{5 \circ} / \mathrm{sec}^{2}$ (for $1000^{\circ} / \mathrm{sec}$ ), and $7.8 \times 10^{5 \circ} / \mathrm{sec}^{2}$ (for $1300 \%$ sec).

For some trials, whisker deflection protocols were coupled to square current pulses injected through the micropipette to record synaptic responses at different membrane potentials. Current pulses were applied at least $200 \mathrm{msec}$ before whisker stimulation to ensure the $\mathrm{Vm}$ had reached steady state and to avoid capacitive artifacts. The amount of current injected was adjusted for each cell depending on its input resistance (Rin) and firing rate at depolarized potentials.

Data analysis. All data analysis was done off-line. Routines for averaging sensory responses were written in IgorPro (Wavemetrics, Lake Oswego, OR). For all cells, whisker-evoked postsynaptic potential amplitudes were measured from the baseline $\mathrm{Vm}$ to the peak of the response. Baseline Vm was calculated as the mean Vm of the $100 \mathrm{msec}$ preceding whisker deflection. Spike threshold (Vthr) was calculated as the value of $\mathrm{Vm}$ at the peak of the second derivative of the $\mathrm{Vm}$ trace within a time window of $2 \mathrm{msec}$ preceding the peak of the spike, which at $10 \mathrm{KHz}$ corresponds with 20 data points. All statistical measures were calculated using Excel (Microsoft, Seattle, WA).

Histology. At the end of each experiment, animals were perfused intracardially with an initial $0.9 \%$ saline solution followed by cold $4 \%$ paraformaldehyde in $0.1 \mathrm{M}$ PBS. Brains were promptly removed and postfixed overnight in the same fixative. Finally, tissue was stored in $0.1 \mathrm{~m}$ sodium phosphate buffer until used. Coronal sections (100 $\mu \mathrm{m}$ thick) were cut in 
a vibratome. After three washes in PBS, sections were preincubated for 1 $\mathrm{hr}$ at room temperature (RT) with $10 \%$ normal goat serum (Vector Laboratories, Burlingame, CA), 1\% bovine serum albumin (Sigma, St Louis, MO), and $0.4 \%$ Triton X-100 (Sigma) in PBS. Sections were then incubated overnight at RT in the previous solution with an additional $0.1 \%$ cyanin 3 (Cy3)-conjugated streptavidin (Jackson ImmunoResearch, West Grove, PA). After several rinses with PBS, tissue was mounted on gelatinized glass slides and coverslipped with Vectashield (Vector Laboratories). For the cytochrome oxidase histochemical reaction, sections were washed three times with PBS and then treated for 30 min with a solution of $10 \%$ ethanol and $2 \% \mathrm{H}_{2} \mathrm{O}_{2}$ in PBS. After several rinses in $\mathrm{PBS}$, tissue was incubated for $2-3 \mathrm{hr}$ at $37^{\circ} \mathrm{C}$ in a freshly prepared solution containing $100 \mathrm{~mm}$ phosphate buffer, $\mathrm{pH}$ 7.4, 0.1\% horse heart cytochrome C (Sigma), $117 \mathrm{~mm}$ sucrose, and $1.4 \mathrm{~mm}$ diaminobenzidine tetrahydrochloride (Wong-Riley, 1979).

Cy3-labeled cells were visualized with an Olympus BX51 microscope (Olympus, Melville, NY) and a filter cube set for tetramethylrhodamine isothiocyanate/DiI/Cy3 (excitation, $540 \mathrm{~nm}$; dichroic, $565 \mathrm{~nm}$; emission, $605 \mathrm{~nm}$; Chroma Technology, Rockingham, VT). Pictures were taken at several focal planes using an Olympus MagnaFire digital camera that was attached to the microscope. The images were saved and then overlayed using Adobe Photoshop (Adobe Systems, San Jose, CA).

\section{Results}

\section{Database}

The results are based on intracellular recordings from layers 2-6 of the rat barrel cortex. Of the 87 cells recorded from 32 rats, a total of 37 cells was included in the database according to the following criteria: (1) overshooting action potentials, (2) a stable resting membrane potential between -65 and $-77 \mathrm{mV}$ during the time required to complete the full battery of protocols $(\sim 40$ $\mathrm{min}$ ), and (3) onset latencies of $<13 \mathrm{msec}$ to minimize the inclusion of cells located above, below, or within the septum (Brecht and Sakmann, 2002; Brecht et al., 2003). The resting Vm was $-71.6 \pm 1.1 \mathrm{mV}$ (mean $\pm \mathrm{SE}$ ), spike threshold was $-52 \pm 3 \mathrm{mV}$, and the Rin was $27.4 \pm 3.0 \mathrm{M} \Omega$ as estimated by the slope of the linear fits to the $\mathrm{Vm}$ values after three current injection levels (see Fig. 4E).

To produce whisker deflections, we used fixed amplitude ramp and hold stimuli with linearly related velocity and acceleration-deceleration profiles (see Materials and Methods). Here, we chose to plot our measurements against velocity only and not acceleration, because this was the parameter that could be more accurately quantified (see Materials and Methods). We acknowledge that acceleration is also increasing and could in fact be the more important parameter (Temereanca and Simons, 2003) of the deflection determining the synaptic response. However, the main thrust of this work is not to characterize the cortical responses to either velocity or acceleration specifically but to understand the effect of increasing stimulus intensity (represented by the velocity-acceleration of the deflection) on the composition of synaptic responses in the different layers of the barrel cortex.

The results will be presented in the following order. First, we will compare the synaptic and spike responses, obtained at the resting $\mathrm{Vm}$ to the deflection of the $\mathrm{PW}$ at the highest stimulus intensity (peak velocity-acceleration of $1300^{\circ} / \mathrm{sec}, 7.8 \times 10^{5 \circ}$ / $\sec ^{2}$ ), between Gr (layer 4), SGr (layers 2-3), and IGr (layers 5-6) cells. Second, we will study the synaptic composition of the responses of Gr, SGr, and IGr cells to the highest stimulus intensity by examining the current-clamp traces at different Vms and the corresponding estimations of apparent synaptic reversal potential and input resistance. Third, we will show by means of population synaptic responses the effect of increasing stimulus intensity (velocity-acceleration) on the synaptic responses of the three groups of cells. Finally, we will propose that the arrangement of synaptic responses is such that Gr cells integrate excitatory inputs only in the first 5-7 msec of the response, whereas in SGr and IGr cells, the time window in which inputs are integrated to generate spike output is longer (13-20 msec) and is not limited by the immediate action of local inhibition as it is in Gr cells.

\section{Responses in different layers}

The synaptic and spike responses were similar among cells in the same layer but markedly different between cells in different layers. Figure 1 illustrates these differences for three cells, each representative of their respective layer. The three cells were filled with neurobiotin and recovered (see Materials and Methods) and are shown at the left (Fig. 1) on a background that has been further processed for cytochrome oxidase to reveal the position of the barrels (SGr is a pyramidal cell at $280 \mu \mathrm{m}$ depth; $\mathrm{Gr}$ is a spiny stellate cell at $710 \mu \mathrm{m}$ depth; IGr is a pyramidal cell at $990 \mu \mathrm{m}$ depth; all measured from the pial surface). Examples of individual responses at the resting $\mathrm{Vm}$ ( $n=5 ; \mathrm{Vm}$ is indicated) to the highest deflection velocity-acceleration $(1300 \% \mathrm{sec}$, $7.8 \times 10^{5 \circ} / \mathrm{sec}^{2}$ ) are superimposed in the left column (Fig. 1), and the average synaptic responses (Fig. 1, AVG, solid traces) $(n=$ 20) are shown in the middle column. The synaptic response, which consisted of an
Figure 1. Differences between cells from different layers. Examples of an SGr cell recorded at $280 \mu \mathrm{m}$ depth, a Gr spiny stellate cell recorded at $710 \mu \mathrm{m}$, and an $\mathrm{IGr}$ cell with a bitufted apical dendrite recorded at $990 \mu \mathrm{m}$ are shown. Cells were photographed and superimposed on a background of cytochrome oxidase-treated tissue. Cells were placed according to their original positions and are shown on the same background for simplicity. The axon of the spiny stellate cells can be seen ascending toward supragranular layers. The left columnshows superimposed individual responses $(n=6)$ at the resting Vm (indicated) to the highest velocity. Averages (AVG; $n=21$ ) are shown in the middle column. The right column shows the PSTHs (bin, $1 \mathrm{msec}$ ); firing rate is indicated. At the bottom of the right column, the responses to the highest velocity from the three cells were superimposed to highlight their differences. Spks/Stim, Spikes per stimulus. 
EPSP followed by an IPSP, was very consistent across trials. The IPSP at rest had a latency to peak longer than $60 \mathrm{msec}$ and will be referred to as the late IPSP. Off-responses were variable and dependent on the direction tuning of the cell; therefore, they will not be discussed further. All responses described henceforth are to the onset of the stimulus. The peak amplitude of the EPSP was comparable for the three cells (SGr, $9.2 \mathrm{mV}$; Gr, $9.4 \mathrm{mV}$; IGr, $10.6 \mathrm{mV}$ ), but differences were apparent in four other parameters. The response of the SGr cell had a smaller $\mathrm{dV} / \mathrm{dt}(1.0 \mathrm{mV} / \mathrm{msec})$ and a longer duration (19.5 $\mathrm{msec}$ ) than the two other cells ( $\mathrm{Gr}, 2.0 \mathrm{mV} / \mathrm{msec}$ and $14 \mathrm{msec}$; IGr, $1.8 \mathrm{mV} / \mathrm{msec}$ and $16 \mathrm{msec}$ ), whereas the $\mathrm{Gr}$ cell had a shorter latency to onset $(6.9 \mathrm{msec})$ and to peak $(11 \mathrm{msec})$ than the other two cells (SGr, 9.5 and $20 \mathrm{msec}$; IGr, 9.0 and $18.7 \mathrm{msec}$ ). The averages were superimposed to highlight these differences (Fig. 1, bottom right). The differences in the synaptic responses were paralleled by the spike output (Fig. 2, right column). The Gr cell produced the spike response with the shortest latency and duration, and the SGr cell produced the spike response with the longest duration. The amplitude of the response in spikes per stimulus was highest for the SGr cell ( 0.45 spikes/stimulus) followed by the Gr cell ( 0.30 spikes/stimulus) and the IGr cell ( 0.25 spikes/stimulus). However, the differences in spike rate were not representative, because the means of the populations are not significantly different.

To verify whether the differences between the three example cells illustrated above were consistent for the entire population, we grouped cells according to depth (SGr: 230-480 $\mu \mathrm{m}, n=11$; Gr: $550-850 \mu \mathrm{m}, n=12$; IGr: $1000-1500 \mu \mathrm{m}, n=14)$ and calculated the mean of each group for a number of parameters measured from the response to the highest velocity-acceleration (Fig. 2). In Figure 2A, the values from individual cells are plotted against cell depth, and the mean and SE of each group are represented as histogram bars at the right. The recovered cells $(n=15)$ are indicated by filled symbols (Fig. 2) in the top left plot. The position of recovered cells was $<40 \mu \mathrm{m}$ apart from the position read on the micromanipulator. In five of the measurements, one group was significantly different $(F>3)$ (Fig. 2, asterisk) from the other two: (1) the latency to onset of the EPSP was shortest in Gr cells $(\mathrm{SGr}=9.7 \pm 0.3 \mathrm{msec} ; \mathrm{Gr}=7.0 \pm 0.4 \mathrm{msec} ; \mathrm{IGr}=9.7 \pm$ $0.6 \mathrm{msec}$; one-way ANOVA; $p<0.001$ ), (2) the latency to the peak of the EPSP was shortest in Gr cells ( $\mathrm{SGr}=21.9 \pm 1.2 \mathrm{msec}$; $\mathrm{Gr}=15.0 \pm 0.5 \mathrm{msec} ; \mathrm{IGr}=19.1 \pm 0.8 \mathrm{msec} ; p<0.0001),(3)$ the rate of rise of the EPSP was lowest (i.e., the value of the $\mathrm{dV} / \mathrm{dt}$ was smaller) in SGr cells ( $\mathrm{SGr}=0.6 \pm 0.1 \mathrm{mV} / \mathrm{msec} ; \mathrm{Gr}=1.2 \pm 0.1$ $\mathrm{mV} / \mathrm{msec}, \mathrm{IGr}=1.1 \pm 0.1 \mathrm{mV} / \mathrm{msec} ; p<0.0001$ ), (4) the duration of the EPSP measured at half amplitude was longest in SGr cells $(\mathrm{SGr}=20.5 \pm 1.1 \mathrm{msec} ; \mathrm{Gr}=14.3 \pm 0.7 \mathrm{msec} ; \mathrm{IGr}=14.5 \pm$ $0.8 \mathrm{msec} ; p<0.0001$ ), and (5) the latency to the peak of the late IPSP was longest in supragranular cells $(\mathrm{SGr}=80.5 \pm 2.2 \mathrm{msec}$; $\mathrm{Gr}=68.9 \pm 2.0 \mathrm{msec} ; \mathrm{IGr}=71.5 \pm 2.1 \mathrm{msec} ; p<0.005)$. Values from the other three measurements were not significantly different between the three groups, namely (1) the amplitude of the $\operatorname{EPSP}(\mathrm{SGr}=5.5 \pm 0.9 \mathrm{mV} ; \mathrm{Gr}=7.9 \pm 0.7 \mathrm{mV} ; \mathrm{IGr}=7.0 \pm 0.7$ $\mathrm{mV} ; p>0.1)$, (2) the number of spikes per stimulus ( $\mathrm{SGr}=$ $0.17 \pm 0.11$ spikes/stimulus; $\mathrm{Gr}=0.25 \pm 0.08$ spikes/stimulus; $\mathrm{IGr}=0.23 \pm 0.07$ spikes/stimulus; $p>0.5)$, and (3) the amplitude of the late IPSP $(\mathrm{SGr}=2.1 \pm 0.3 \mathrm{mV} ; \mathrm{Gr}=2.8 \pm 0.5 \mathrm{mV}$; $\mathrm{IGr}=2.3 \pm 0.3 \mathrm{mV} ; p>0.05)$. Thus, as previously illustrated by the examples in Figure 1, the response of Gr cells occurred earlier (both Vm and spike output) than SGr and IGr cells, which had similar latencies to onset, and the response of SGr cells had a longer duration than Gr and IGr cells. IGr cells were not statistically different in any one single parameter, but they could still be delineated from the other two groups by their synaptic response

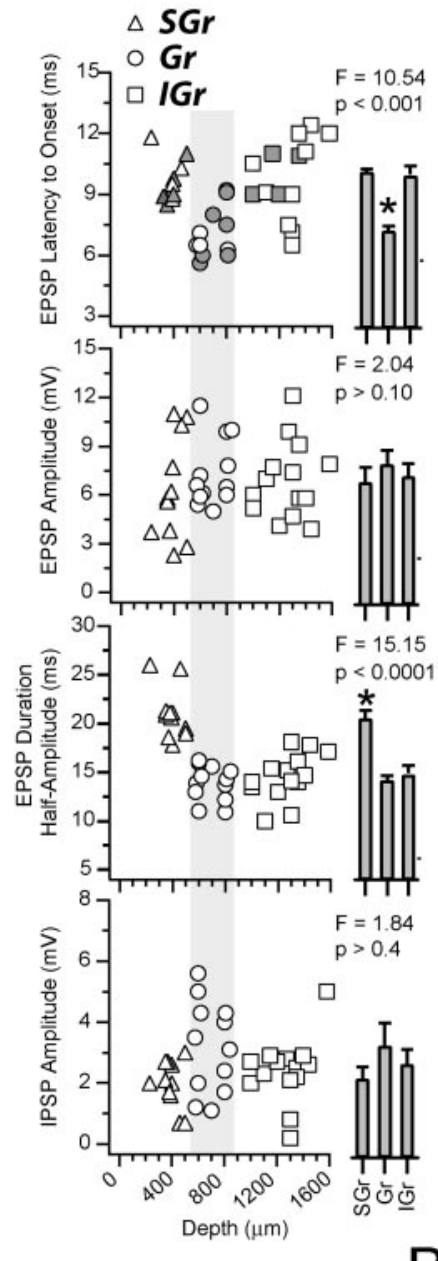

A
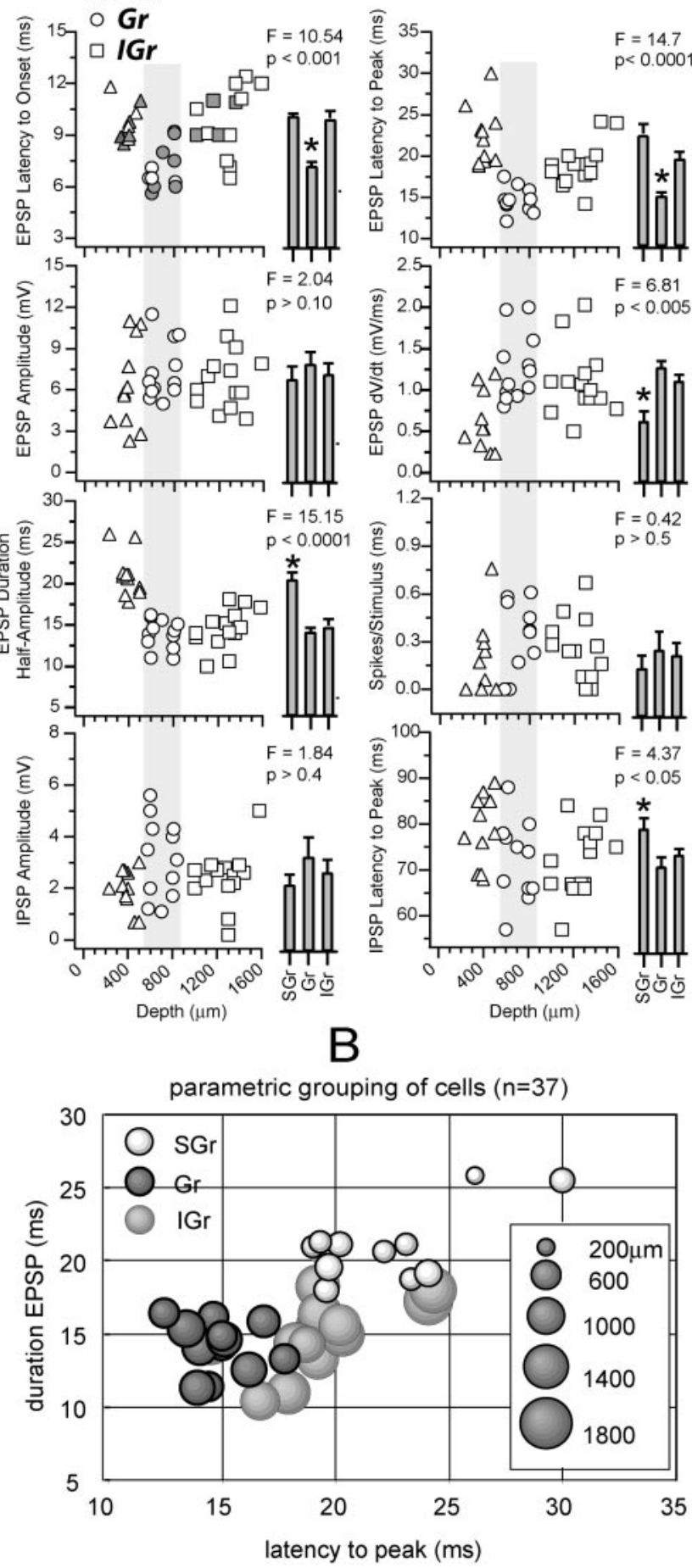

Figure 2. Parameter values from all cells in the database. $A$, Each plot represents the value of the parameter indicated by the label on the $y$-axis against the depth of the cell ( $x$-axis). Triangles represent SGr cells $(n=11 ; 230-480 \mu \mathrm{m})$, circles represent Gr cells $(n=12$; $550-850 \mu \mathrm{m})$, and squares represent IGr cells ( $n=14 ; 1000-1500 \mu \mathrm{m})$. Histograms at right are the mean \pm SE for each of the three groups of cells. Groups were compared with a one-way ANOVA, and significant differences (one group different from the other two; $F$ and $p$ values are indicated) are highlighted with an asterisk. Gray symbols in the top left plot indicate the cells that were recovered histologically. $B$, A parametric representation of the cells is shown to illustrate that, although IGr cells (light gray) are not significantly different in any single parameter, they can be separated from Gr (dark gray, black outline) and SGr (white, black outline) cells on the basis of their long peak latency and narrow EPSP. Cell depth is represented as diameter of the circle (scale at right). 
profile. By plotting the values of two parameters against each other (Fig. 2B), the IGr cell population was distinguished in the parametric plot because of their unique long latency and short duration EPSP.

Because the synaptic responses of cells within a layer were very similar in shape, we averaged across cells (same cells as in Fig. 2) to generate a population synaptic response for each layer. Instead of comparing only discrete time points as in Figure 2, population synaptic responses allow comparisons between layers and between velocities as a continuous function of time. Population peristimulus time histograms (PSTH) were also constructed by accumulating the spike responses from the cells in each layer. Figure $3 \mathrm{~A}$ shows the three population synaptic responses (SGr, $\mathrm{Gr}$, and IGr) to the highest velocity-acceleration at rest (continuous traces) superimposed on the corresponding population PSTHs. The population responses (both synaptic and PSTH) capture the essential differences between layers shown by the three cells in Figure 1 and the means of the populations in Figure 2. The population synaptic response of SGr cells (Fig. 3A, SGr) had an amplitude of $4.4 \mathrm{mV}$ and a duration at half amplitude of $26.2 \mathrm{msec}$, the response of Gr cells (Fig. $3 \mathrm{~A}, \mathrm{Gr}$ ) had an amplitude of $5.9 \mathrm{mV}$ and a duration of $18.9 \mathrm{msec}$, and the response of IGr cells (Fig. $3 \mathrm{~A}$, IGr) had an amplitude of $6.4 \mathrm{mV}$ and a duration of $18.5 \mathrm{msec}$. Gr cells had the shortest latency to onset $(7.3 \mathrm{msec})$ followed by IGr $(9.4 \mathrm{msec})$ and SGr $(9.8 \mathrm{msec})$ cells. Gr cells also had the shortest latency to peak ( $15.1 \mathrm{msec})$ followed by IGr (18.8 msec) and SGr (23.5 msec) cells. The latency to peak of the SGr population synaptic response was longer, resulting from a slower rate of rise and a broader peak. The differences in the population synaptic responses to the highest velocity-acceleration were reflected in the corresponding population PSTHs. Because of the steep rise (large $\mathrm{dV} / \mathrm{dt}$ ) of the population synaptic response of $\mathrm{Gr}$ and IGr cells, the peak of the PSTH occurred during the rising phase and before the peak of the synaptic response. However, the population PSTH of Gr cells showed a faster and more pronounced decay than that of IGr cells despite synaptic responses of similar durations, suggesting that Gr cells are subjected to stronger inhibition. In contrast, the slower rate of rise ( small $\mathrm{dV} / \mathrm{dt}$ ) of the population synaptic response of SGr cells resulted in a population PSTH with a time course comparable with the underlying EPSP. The latency to the peak of the population PSTHs was 28.5 msec for SGr cells, $11.2 \mathrm{msec}$ for Gr cells, and $15 \mathrm{msec}$ for IGr cells. In Figure $3 B$, the population responses were superimposed to highlight the differences in timing discussed above. The population synaptic responses were normalized to the peak (indicated by arrows) to make the comparison clearer. In summary, the peak of the synaptic and spike (PSTH) response of the Gr cells was followed by the IGr and then by the SGr cells.

\section{Synaptic components of the response}

To study the synaptic components of the response, we repeated the stimulation protocol while displacing the Vm with square current pulses (Fig. 4). Current pulses started $200 \mathrm{msec}$ before the whisker deflection to ensure a stable Vm at the time of the synaptic response. By measuring the synaptic responses at different Vms, one can estimate the Rin and the apparent reversal potential (Vrev) during the response. An example of the procedure for a $\mathrm{Gr}$ cell is illustrated in Figure 4 (830 $\mu \mathrm{m}$ depth). The PW was deflected at the highest velocity-acceleration while the cell was held at a depolarized $\mathrm{Vm}(-58 \mathrm{mV},+0.6 \mathrm{nA})$, at rest $(-67 \mathrm{mV}, 0 \mathrm{nA})$, and at a hyperpolarized $\mathrm{Vm}(-82 \mathrm{mV},-0.8 \mathrm{nA})$. Single trial responses (Fig. 4A) (four superimposed traces for each $\mathrm{Vm}$ ) showed an EPSP that occasionally led to spikes. We averaged the
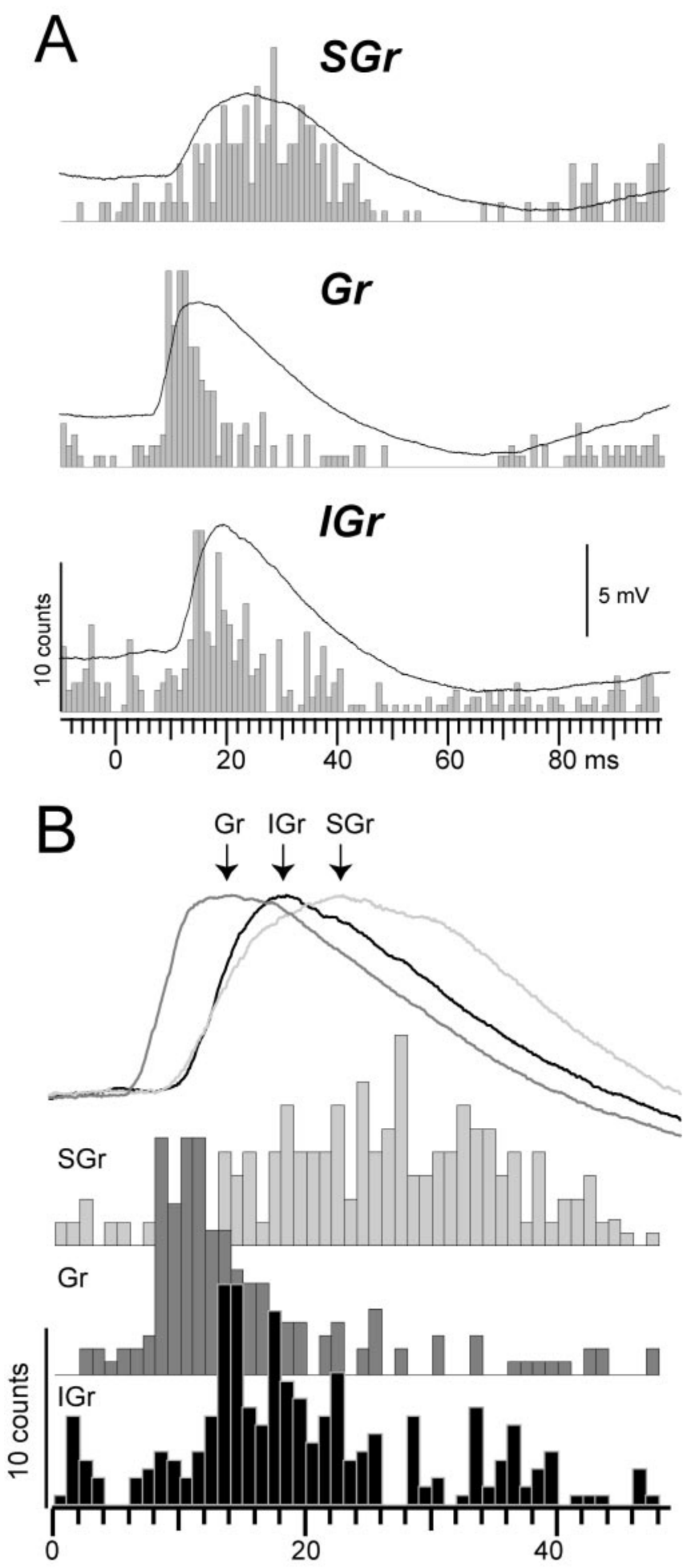

Figure 3. Average responses from the three populations of cells. $A$, The $\mathrm{Vm}$ traces are the population synaptic responses at the highest velocity-acceleration $\left(1300 \% \mathrm{sec} ; 7.8 \times 10^{5 \circ} / \mathrm{sec}^{2}\right)$ and at the resting Vm. The population PSTH (bin size, $1 \mathrm{msec}$ ) was constructed by adding the spike counts from the same responses. $B$, Synaptic responses were scaled to their peaks and superimposed to illustrate differences in shape and time course. PSTHs are partially overlapped to illustrate the sequential output of the layers after sensory activation.

responses for each Vm (Fig. $4 B)(n=12)$ excluding those responses that triggered spikes to avoid contamination by the spike afterhyperpolarization. Eliminating spike contamination is extremely important, because the accuracy of the estimations of 

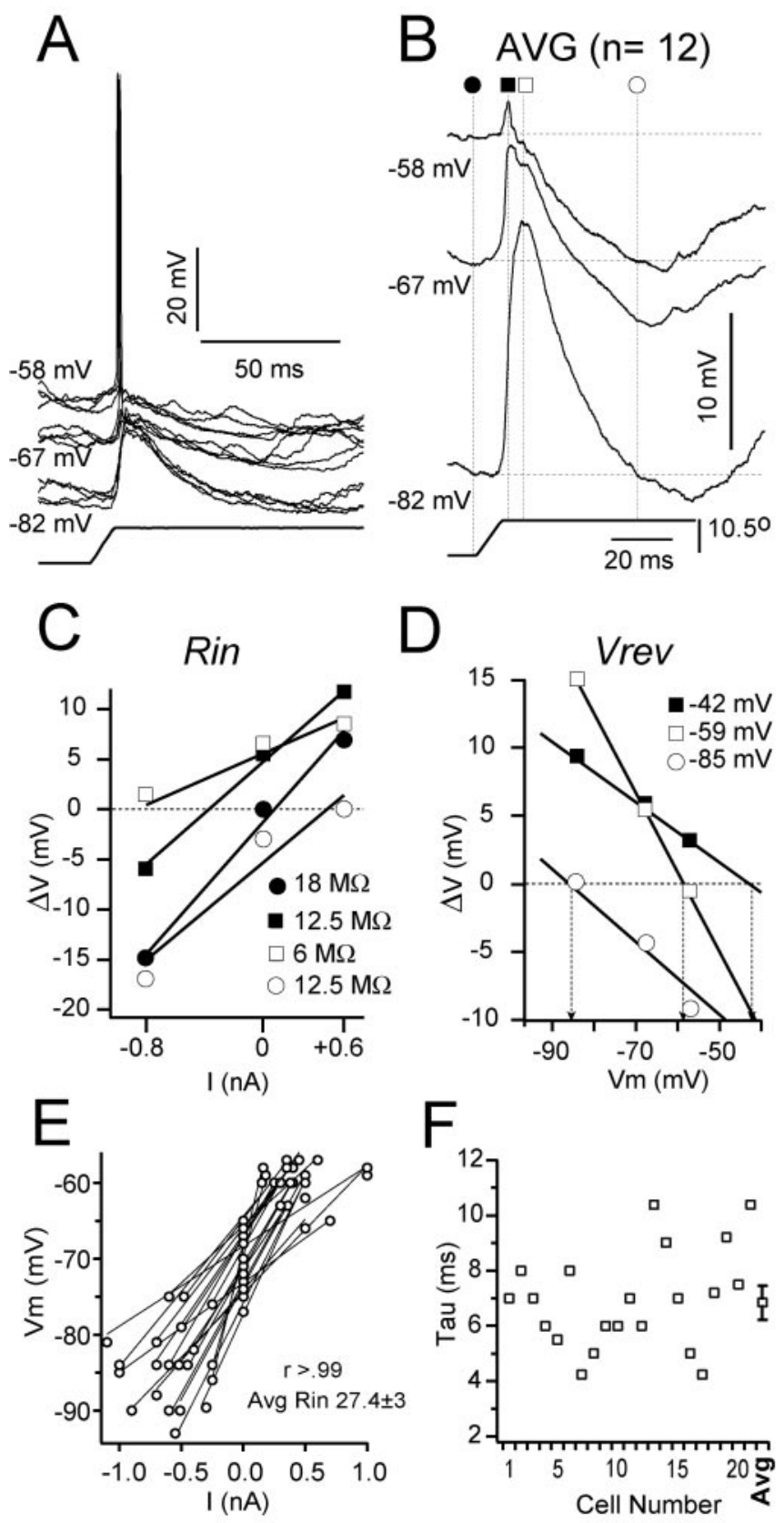

Figure 4. Synaptic responses to the deflection of the PW at different $V m s$. Recording is from a $\mathrm{Gr}$ cell at $850 \mu \mathrm{m}$ depth. $A$, Superimposed individual responses $(n=4)$ to the highest velocity-acceleration at three different current levels: depolarized $(-58 \mathrm{mV}$; $+0.6 \mathrm{nA})$, rest $(-67 \mathrm{mV} ; 0 \mathrm{nA})$, and hyperpolarized $(-82 \mathrm{mV} ;-0.8 \mathrm{nA})$. B, Average responses $(n=23)$ at each $V \mathrm{~m}$ (indicated). Symbols and dotted lines indicate the time at which measurements were made. C, Plot of change in $V m$ from rest $(\Delta V)$ against injected current $(V--/$ plot) used to calculate Rin. $D$, Plot of change in $V m$ from rest $(\Delta V)$ against baseline Vm used to calculate Vrev. Rin and apparent Vrev were calculated as the best linear regression fit to each set of values obtained from the time points indicated in $B$ (values indicated). E, Plot of Vm versus injected current (3 levels in all cases) from 11 cells and the corresponding linear fits; $r>0.99$ in all cases. Rin was the slope of the fitted line, and the average for the population shown in the graph was $25.4 \pm 3 \mathrm{M} \Omega$. F, Time constant from the same 11 cells was calculated by fitting an exponential to the onset of small (0.2-0.5 nA) hyperpolarizing pulses. Values varied between 4 and $11 \mathrm{msec}$ with a mean of $6.9 \pm 0.5 \mathrm{msec}$ (mean $\pm \mathrm{SE}$ ) indicated at right (AVG). apparent Vrev and Rin, which are based on the current-clamp values of the average $\mathrm{Vm}$, depending on how much the $\mathrm{Vm}$ is dominated by the synaptic currents that underlie the response. Because in our current-clamp recordings spike generation is not blocked, there is an inevitable bias toward subthreshold responses, which in turn leads to a small underestimation of the excitatory currents underlying the EPSP. Such an inevitable bias is caused by the spike threshold and not by elimination of suprathreshold trials, because once threshold is crossed, the $\mathrm{Vm}$ is entirely dominated by the action potential; therefore, only Vm fluctuations occurring below, but not above, threshold contribute to the average response.

In six cells, we assessed how the average synaptic response was affected by the exclusion of suprathreshold trials. These cells were chosen because their action potentials had little or no afterhyperpolarization or ADPs. For spike removal, an algorithm located the start of the spike (the peak of the second derivative of the $\mathrm{Vm}$ ) and the end of the spike (where the Vm had returned to the value at the start of the spike) and inserted a flat line between the two points. Spike duration was between 0.8 and $1.2 \mathrm{msec}$. Before averaging, the trace was low-pass filtered to smooth the abrupt transitions caused by the insertion of the flat line. Compared with the averages using all trials, the corresponding averages using only subthreshold responses were slightly smaller $(<10 \%)$, but there was not a detectable difference in $\mathrm{dV} / \mathrm{dt}$. However, when examining the individual trials, we observed numerous examples of subthreshold trials that were of higher amplitude than suprathreshold trials resulting from the variability in the Vm.

At rest $(-67 \mathrm{mV})$, the response consisted of an EPSP followed by a late IPSP (described in Fig. 1). Depolarization $(-58 \mathrm{mV}$ ) from rest reversed the polarity of all but the first $5 \mathrm{msec}$ of the EPSP, revealing an early IPSP that truncated the initial EPSP. Hyperpolarization $(-82 \mathrm{mV})$ enhanced the amplitude of the response at rest and almost entirely reversed the late IPSP. We estimated Rin and apparent Vrev at three time points during the response (Fig. $4 B$ ): the peak of the EPSP at the depolarized Vm (filled squares), the peak of the response at the hyperpolarized $\mathrm{Vm}$ (which corresponds with the peak of the early IPSP; open squares), and an arbitrary point near the peak of the late IPSP (open circles). In addition, we measured baseline Rin (Fig. $4 B$, filled circles). To estimate Rin, we plotted the value of the change in $\mathrm{Vm}$ from baseline $(\Delta \mathrm{V})$ against injected current ( $\mathrm{V}-\mathrm{I}$ plot) (Fig. $4 C$ ). The value of Rin was defined as the slope of the best least-squares linear fit for each set of data points in the $V-I$ plot. The baseline Rin was $18 \mathrm{M} \Omega$ (filled circles), dropped to $12.5 \mathrm{M} \Omega$ at the peak of the EPSP under depolarization (filled squares), was only $6 \mathrm{M} \Omega(67 \%$ drop) at the peak of the response under hyperpolarization (open squares), and then returned to a value of 12.5 $\mathrm{M} \Omega$ near the peak of the late IPSP (open circles). To estimate the apparent Vrev, we plotted the value of $\Delta V$ against the value of the baseline $\mathrm{Vm}$. The apparent Vrev was defined as the value of $\mathrm{Vm}$ (marked with vertical arrows) at the zero crossing (Fig. 4D, dotted line) of the regression lines. The apparent Vrev was $-42 \mathrm{mV}$ at the peak of the EPSP under depolarization (filled squares), $-59 \mathrm{mV}$ at the peak of the response under hyperpolarization (open squares), and $-85 \mathrm{mV}$ during the late IPSP (open circles).

The value of Vrev is the apparent synaptic reversal potential (i.e., the $\mathrm{Vm}$ recorded from the soma at which the synaptic response reverses polarity), and it represents an estimation of the equilibrium potential of the ionic species flowing through the synapse. As such, it is only suggestive of the underlying currents because it is subject to errors attributable to the electrotonic distance of the recording pipette to the site of the synapse. The Vrev 
of $-59 \mathrm{mV}$ at the peak of the response under hyperpolarization together with its pronounced drop in Rin $(\sim 67 \%)$ suggests an underlying $\mathrm{Cl}^{-}$-mediated $\mathrm{GABA}_{\mathrm{A}}$ IPSP. The Vrev of the late IPSP $(-85 \mathrm{mV})$ and the smaller drop in Rin $(\sim 30 \%)$ suggests an underlying $\mathrm{K}^{+}$current. Finally, the Vrev of $-42 \mathrm{mV}$ suggests that the peak of the EPSP recorded under depolarization results from a mixture of an excitatory conductance (probably AMPA and NMDA) (Feldmeyer et al., 1999) with the inhibitory conductance that generates the early IPSP (probably GABA ${ }_{\mathrm{A}}$ ).

The estimation of the apparent Vrev and Rin under current clamp is based on the measurement of Vm values at different resting Vms. These measurements may be contaminated by the activation of intrinsic membrane currents, and therefore it is critical to evaluate the linearity of the cell membrane in the range used for measurement. Our cells were linear in the range used to estimate Vrev and Rin (Fig. $4 E$ ). The examples $(n=20)$ shown in Figure $4 E$ had linear fits with $r$ values $>0.99$, yielding an average Rin of $27.4 \pm 3 \mathrm{M} \Omega$.

Because cells in different layers were grouped to calculate population synaptic responses, it is important to make sure that basic biophysical properties are not widely different. One such property is the time constant (Tau) (Fig. $4 F$ ). Tau had similar values across cells varying between 4 and $11 \mathrm{msec}$ with a mean of $6.9 \pm$ $0.5 \mathrm{msec}$.

The composition of the synaptic response of SGr and IGr cells was different from that of the Gr cell described above. Figure 5 shows an example of a cell from each layer at three Vms. The average responses were artificially displaced to the same baseline (horizontal dotted line) to highlight the differences between cells revealed by the change in $\mathrm{Vm}$. The two main differences in the current-clamp traces were the shift in the latency to peak (vertical dotted arrows) and the reduction in the duration of the EPSP (measured at baseline). Because the EPSP is measured at baseline, changes in duration are a measure of how much of the response reverses polarity with the change in $\mathrm{Vm}$. From the hyperpolarized $(-82 \mathrm{mV})$ to the depolarized $(-58 \mathrm{mV}) \mathrm{Vm}$, the response of the Gr cell was reduced in duration from $61.7-8 \mathrm{msec}$, the peak latency was reduced from $18.8-10.9 \mathrm{msec}$, and the peak amplitude was reduced from 12.7-4.2 mV. In the SGr and IGr cells, a similar change in the $\mathrm{Vm}$ (SGr: from -81 to $-58 \mathrm{mV}$; IGr: from -80 to $-59 \mathrm{mV}$ ) reduced the peak amplitude by an amount comparable with the Gr cell (SGr: 11.1-3.5 mV; IGr: 11.6-4.6 $\mathrm{mV}$ ) but caused a much smaller reduction in the duration (SGr: $41.0-23.8 \mathrm{msec}$; IGr: $40.2-18.5 \mathrm{msec}$ ) and in the latency to peak (SGr: 23.8-20.9 msec; IGr: 18.9-18.1 msec) (Fig. 5, vertical dotted arrows). Therefore, after the first 5-7 msec, the synaptic response of the Gr cell is dominated by conductance with a Vrev below $-60 \mathrm{mV}$, presumably $\mathrm{Cl}^{-}$currents flowing through $\mathrm{GABA}_{\mathrm{A}}$ receptors. In contrast, a powerful IPSP after the initial EPSP is absent in the response of SGr and IGr cells. To support the conclusions reached by the observation of the current-clamp traces, we calculated the values of apparent Vrev and Rin as a continuous function of time by applying the method described in Figure 4 to every data point in the response (Fig. 5, bottom plots). This technique has been successfully applied before in comparable in vivo experiments (Moore and Nelson, 1998; Anderson et al., 2000, 2001; Monier et al., 2003), and Monier et al. (2003) obtained the same values when measuring the input conductance in current-clamp mode and in voltage-clamp mode, thereby prompting them to consider both methods equally valid. During the Gr cell synaptic response, Rin dropped sharply by $50 \%$ to a peak minimum of 15.0 $\mathrm{M} \Omega$ (Rin at rest, 29.6 M $\Omega$ ) and peak latency of $20.7 \mathrm{msec}$ and then returned slowly to baseline. The

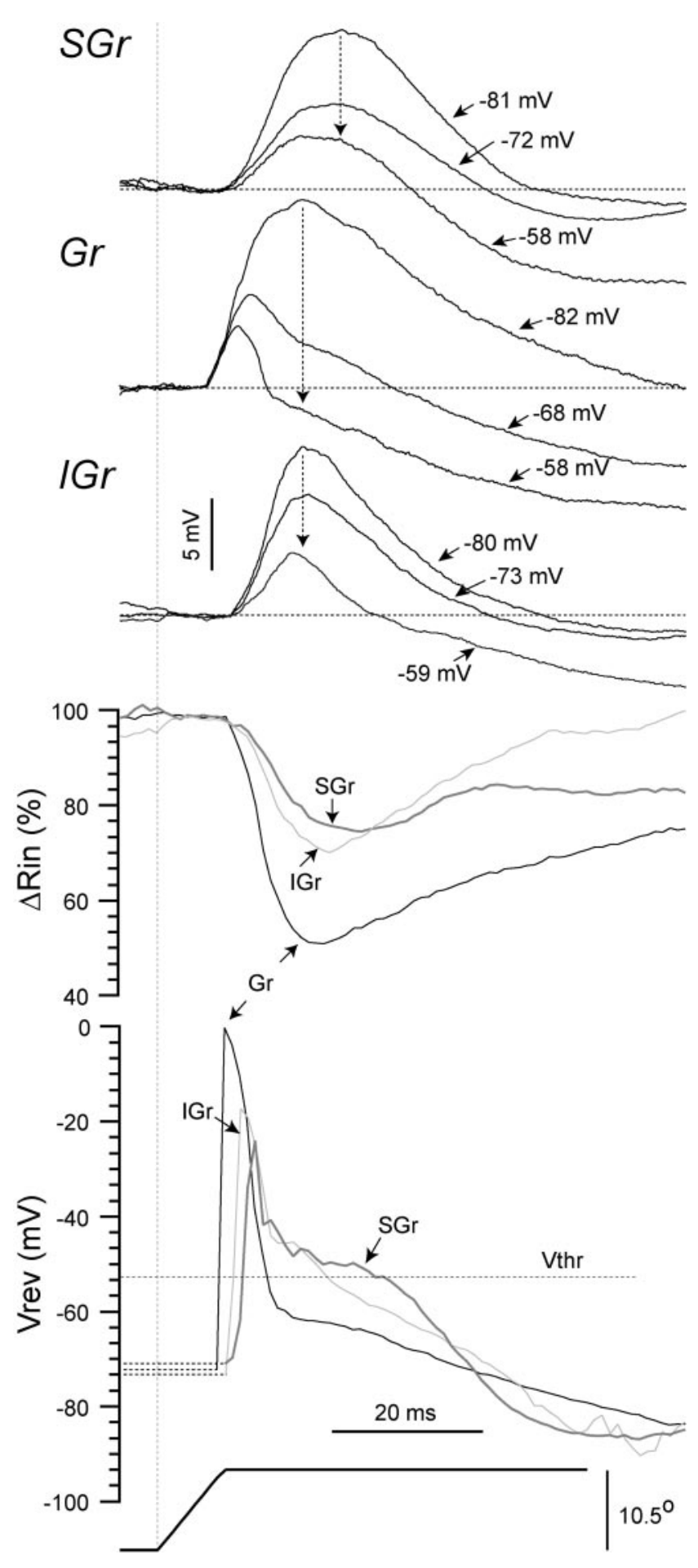

Figure 5. The differences in synaptic responses, Rin, and Vrev between layers. Three example cells, one from each layer $(\mathrm{SGr}, \mathrm{Gr}$, and $\mathrm{IGr}$ ), are shown responding to the highest velocityacceleration (ramp and hold deflection represented at bottom) at their resting $\mathrm{Vm}$, at a depolarized level, and at a hyperpolarized level (Vm is indicated). Below the average synaptic responses ( $n=15$ deflections) are the continuous plots of Rin and apparent Vrev that were obtained using the method illustrated in Figure 4. Mean Vthr is indicated ( $-52 \mathrm{mV})$. Scale bars for the stimulus are the same for the three cells.

synaptic response of the SGr and the IGr cells was associated with peak drops of Rin of only 26 and $30 \%$ at 32 and $22 \mathrm{msec}$, respectively. The initial portion of the Vrev plots (Fig. $5 B$, bottom traces) is not defined (dotted lines), because $\Delta \mathrm{V}$ is zero for all $\mathrm{Vms}$ at baseline. The plot of Vrev calculated from the synaptic 
response of the $\mathrm{Gr}$ cell showed an early peak at $0 \mathrm{mV}$ followed by a sharp drop to $-60 \mathrm{mV}$ and then a slow drop to a minimum of $-84 \mathrm{mV}$. This result is in agreement with the continuous apparent Vrev values reported by Moore and Nelson (1998). The early Vrev peak occurred $3 \mathrm{msec}$ after response onset during the rising phase and before the peak of the EPSP. In our current-clamp recordings, we cannot determine the differential contribution of NMDA- and AMPA-mediated currents (Feldmeyer et al., 1999). The apparent Vrev plots from the SGr and IGr cell synaptic responses had peaks of $-24 \mathrm{mV}$ (at $12.7 \mathrm{msec}$ ) and $-17 \mathrm{mV}$ (at $10.8 \mathrm{msec}$ ), respectively, which also preceded the peak of their corresponding EPSPs. However, in neither case was there a following Vrev at $-60 \mathrm{mV}$, in agreement with the absence of a dominant early IPSP in the current-clamp traces. Instead, the apparent Vrev was between -40 and $-50 \mathrm{mV}$, which is consistent with a combination of excitatory and inhibitory conductance. This apparent Vrev, compared with the value of Gr cells, could result from either a larger excitatory conductance or a smaller inhibitory conductance. Given that the change in input conductance associated with the response of SGr and IGr cells is smaller than that of Gr cells, the values of Rin and apparent Vrev suggest that there is a less powerful inhibitory conductance and a smaller total conductance change associated with the response of SGr and IGr cells. The strength and composition of the excitatory conductance (AMPA vs NMDA) cannot be ascertained. The most valuable information in the plots of apparent Vrev is derived from the comparison of the value of Vthr. In the Gr cell, Vrev drops below Vthr after only $6 \mathrm{msec}$, whereas in the SGr and IGr cells, that occurs after 17.5 and $12.3 \mathrm{msec}$, respectively. This indicates that $6 \mathrm{msec}$ after the onset of the response, the $\mathrm{Vm}$ of the Gr cell is dominated by currents that will tend to hold the Vm below threshold and are therefore inhibitory regardless of the polarity of the current-clamp trace. Consequently, the Gr cell is unlikely to integrate inputs to increase its spike output beyond the first $6 \mathrm{msec}$ of the response. This is strongly supported by the large drop in Rin $(\sim 50 \%)$ at the time Vrev crosses below Vthr, which indicates the inhibitory current is very powerful. In contrast, in SGr and IGr cells, Vrev stays above Vthr longer, and the drop in Rin is smaller $(<30 \%)$, allowing additional time for EPSPs to be integrated and increase spike output.

In summary, the current-clamp data, supported by the apparent Vrev and Rin plots, suggest that the synaptic response in $\mathrm{Gr}$ cells is attributable to the activation of a fast excitatory conductance (probably AMPA and NMDA), followed by an early inhibitory conductance (probably $\mathrm{Cl}^{-} \mathrm{GABA}_{\mathrm{A}}$ mediated), which dominates the $\mathrm{Vm}$, and then followed by a late inhibitory conductance (probably $\mathrm{K}^{+}$). In contrast, in SGr and IGr cells, the excitatory and inhibitory conductances primarily overlap and are followed by the activation of a $\mathrm{K}^{+}$conductance.

\section{Characteristics of the response at rest to increasing stimulus intensity}

To study the synaptic response and spike output as a function of stimulus intensity (velocity-acceleration), we used five randomly interleaved values of velocity-acceleration (see Materials and Methods). Figure 6 shows an example of the responses of a $\mathrm{Gr}$ cell (850 $\mu \mathrm{m}$ depth) at the resting $\mathrm{Vm}(-67 \mathrm{mV})$. The synaptic response to all five deflection velocities (indicated above the traces) consisted of an EPSP followed by a late IPSP and was very consistent across trials even for the lowest velocities, as shown by the superposition of individual responses (Fig. 6A; 12 per velocityacceleration, arrowhead indicates onset of deflection). Offresponses are visible to the two highest deflection velocity-accel-
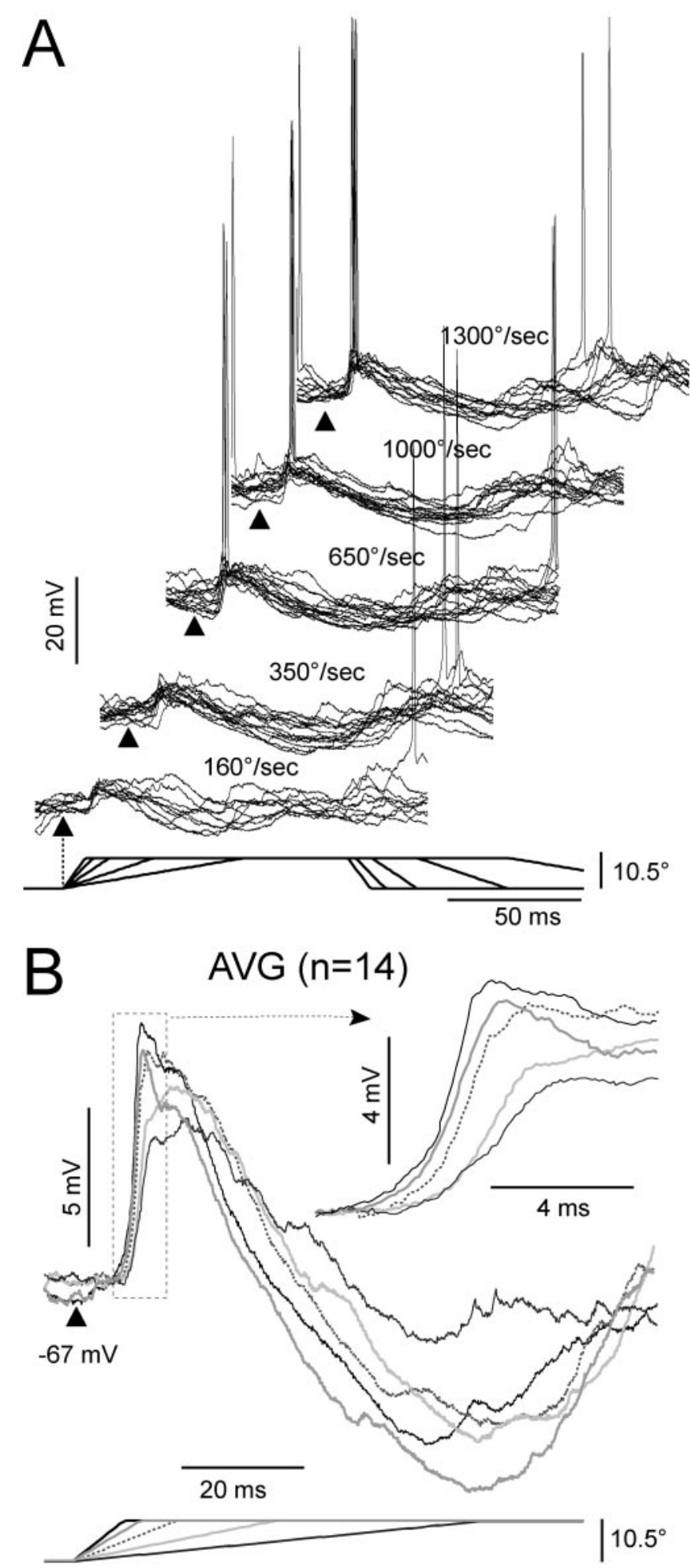

Figure 6. Responses to deflection of the PW at increasing values of velocity-acceleration. Responses are at the resting $\mathrm{Vm}(-67 \mathrm{mV})$ from a cell recorded at $850 \mu \mathrm{m}$ depth. $A$, Single trial responses ( $n=10$ or 12 ) are superimposed for each of the five velocities (indicated above each group of responses). Traces were artificially offset in the $x$-and $y$-axis for clarity. Ramp and hold stimulus is represented at the bottom. Triangles indicate the beginning of the stimulus. $B$, Averages from all responses $(n=14)$ at each velocity-acceleration. Each velocity-acceleration is represented according to the stimulus at the bottom. Inset highlights the upstroke of the response (dotted rectangle). 
eration values (Fig. 6A). The responses to the two lower velocities-accelerations ( 160 and $350^{\circ} / \mathrm{sec}$ ) were subthreshold for action potential generation and were suprathreshold at $650 \% \mathrm{sec}$ ( 0.14 spikes/stimulus), at $1000 \%$ sec ( 0.21 spikes/stimulus $)$, and at $1300 \%$ sec (0.36 spikes/stimulus). The averaged synaptic responses (Fig. $6 \mathrm{~B}, \mathrm{AVG})(n=14$ deflections) show that increasing deflection velocity-acceleration resulted in the following changes in the EPSP (see detail indicated by arrow): (1) an increase in the peak amplitude (from $4.1 \mathrm{mV}$ at $160^{\circ} / \mathrm{sec}$, purple trace, to $6.5 \mathrm{mV}$ at $1300 \%$ sec, blue trace), (2) a decrease in the latency to peak (from $17 \mathrm{msec}$ at $160 \% \mathrm{sec}$ to $11 \mathrm{msec}$ at $1300^{\circ} / \mathrm{sec}$ ), and (3) an increase in the rate of rise $\left(\mathrm{dV} / \mathrm{dt}\right.$; from $0.7 \mathrm{mV} / \mathrm{msec}$ at $160^{\circ} / \mathrm{sec}$ to $1.4 \mathrm{mV} / \mathrm{msec}$ at $1300^{\circ} / \mathrm{sec}$ ) measured between 10 and $80 \%$ of the peak amplitude. The behavior of the late IPSP as a function of velocity-acceleration was less consistent, because the latency to peak did not change ( $\sim 65 \mathrm{msec})$ and the amplitude at the peak was poorly correlated with velocity-acceleration.

To compare the synaptic response at rest as a function of stimulus intensity between the three layers, we used population synaptic responses as well as measurements from the responses of each individual cell (Fig. 7). The population synaptic responses to the highest velocity-acceleration (Fig. 7A) are the same traces shown in Figure 3. To verify that the population responses were not deteriorated by the averaging across cells with different peak latencies, we superimposed on the plots of the population synaptic responses (Fig. 7A) the mean and SE (open symbols) of the latency to peak and peak amplitude calculated from single cell measurements. The measurements from the single cells are obviously made at the peak of each response and therefore, in contrast to the population synaptic responses, the resulting mean is not sensitive to variations in latency among cells. The $y$-coordinate of a symbol is the mean peak amplitude and the corresponding error bars are vertical, and the $x$-coordinate is the mean latency to peak and the corresponding error bars are horizontal. At all velocities, there was a close correspondence between the calculated means and the peaks of the population synaptic responses. The dispersion in both peak parameters, as indicated by the size of the two error bars, was in general very small but was largest in SGr layers and smallest in the Gr layer, indicating that the responses of Gr cells were more homogeneous.

As a function of increasing deflection velocity-acceleration, the latency to peak decreased but the order ( Gr $<\mathrm{IGr}<\mathrm{SGr}$ ) of shortest to longest was maintained (Fig. $7 B$, bottom left). For cells in all layers, the amplitude of the EPSP increased (Fig. 7B, top left) with increasing stimulus velocity-acceleration. The EPSP amplitude was comparable across layers at the higher velocities-accelerations, but differences, albeit small, were apparent between $\mathrm{Gr}$ cells and the other two groups at the lowest velocity-acceleration values. The paucity of suprathreshold responses precluded a comparison between the three groups; nevertheless, the increase in spikes per stimulus with velocity-acceleration (Fig. $7 B$, top right) reported here is consistent with published extracellular data (Pinto et al., 2000). Finally, the dV/dt increased with velocity-acceleration with the value of Gr cells always higher than that of the SGr and IGr cells. To characterize the increase in $\mathrm{dV} / \mathrm{dt}$ with velocity-acceleration, we used the slope of the least-squares best fit linear function to each data set. Each set yielded a Pearson's $r$ value $>0.99$. The increase in $\mathrm{dV} / \mathrm{dt}$ with velocity-acceleration (Fig. $7 B$, bottom right) was smaller in SGr cells $(0.40 \mathrm{mV} /$ msec per $1000 \% \mathrm{sec})$ than in $\mathrm{Gr}(0.68 \mathrm{mV} / \mathrm{msec}$ per $1000 \% \mathrm{sec})$ and IGr cells (and $0.76 \mathrm{mV} / \mathrm{msec}$ per $1000^{\circ} / \mathrm{sec}$ ). Therefore, although
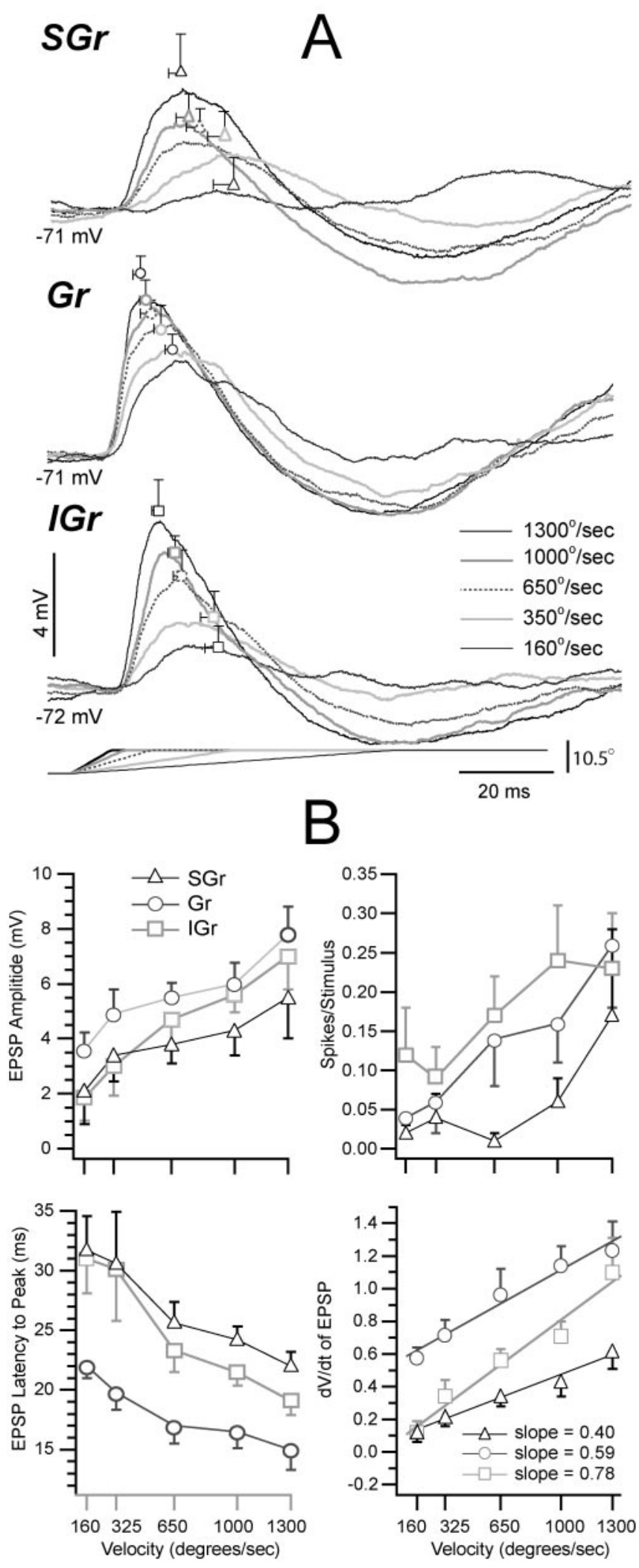

Figure 7. Responses of each population as a function of stimulus intensity (velocity-acceleration). $A$, Population synaptic responses at the resting $V m$ to the five velocity-acceleration values. The values of the mean \pm SE of the latency to peak and the peak amplitude are shown superimposed on the population averages in $A$ at their corresponding $x$-and $y$-axis coordinates. $B$, Scatter plots are the means \pm SE of the parameters indicated in the ordinates, calculated using the measurements obtained from the individual cells in each group. Values are plotted against deflection velocity (and not acceleration; see Materials and Methods). Same symbols as in Figure 2. 


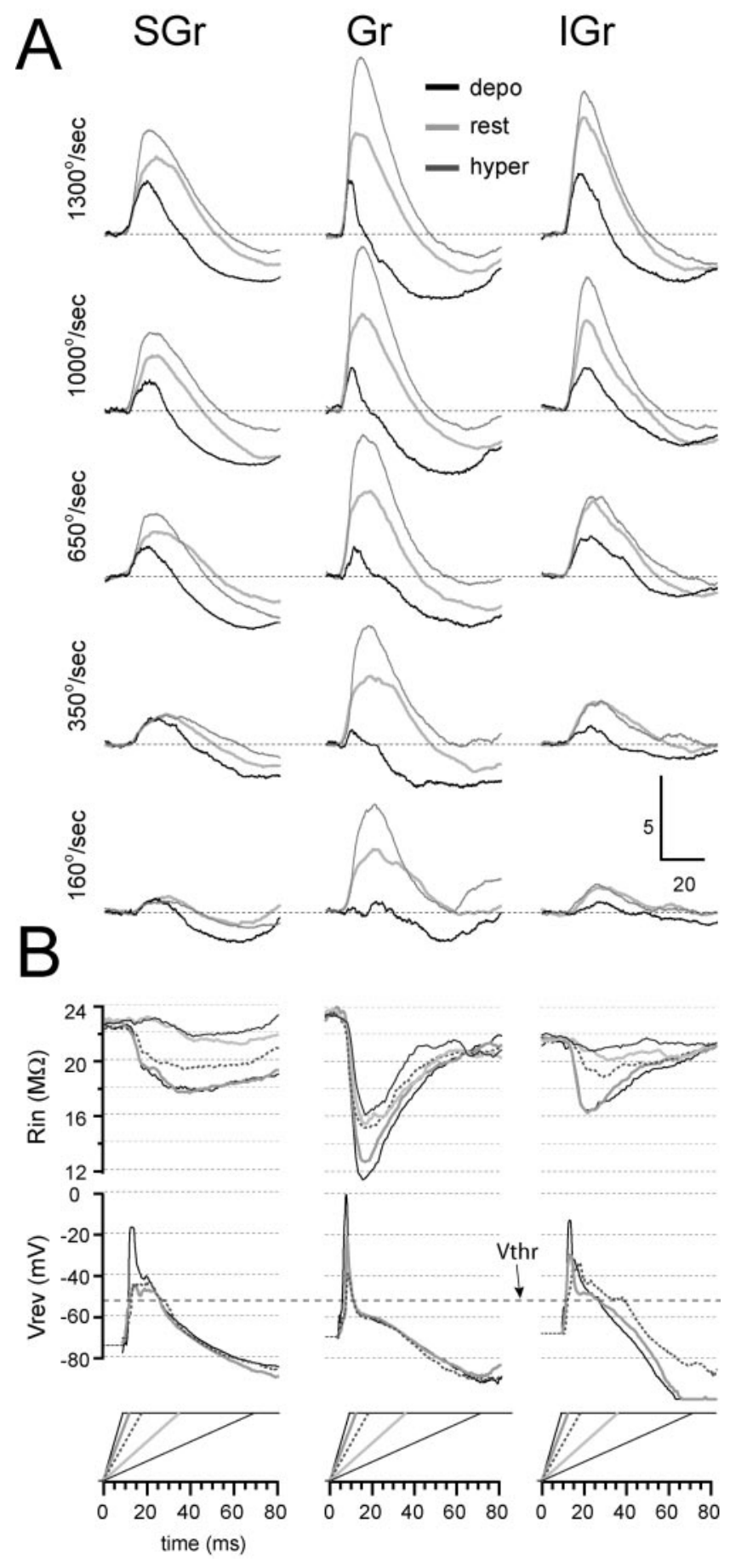

Figure 8. The synaptic composition of the responses as a function of stimulus intensity (velocityacceleration) for the three layers. A, Population synaptic responses of SGr (left column), Gr (middle column), and IGr (right column) cells were calculated from the responses at rest (light gray traces), at a depolarized Vm (depo; black traces), and at a hyperpolarized Vm (hyper; dark gray traces). In each column, the highest velocity-acceleration is represented at the top (deflection velocity is indicated at left). $B$, Continuous plots of apparent Vrev and Rin. The Vrev plots at the two lowest velocities were not calculated because the small amplitude of the responses made the measurements unreliable. The traces in $B$ are coded to the corresponding velocity of the stimulus, which is plotted at the bottom of each column. Mean spike threshold (Vthr; $-52 \mathrm{mV}$ ) is indicated.

at all stimulus intensities Gr cells had the earliest and steepest response, the $\mathrm{dV} / \mathrm{dt}$ of IGr cells was the most sensitive to changes in velocity-acceleration. This result is consistent with the high velocity thresholds reported for layer 5 neurons (Ito, 1985, 1992).

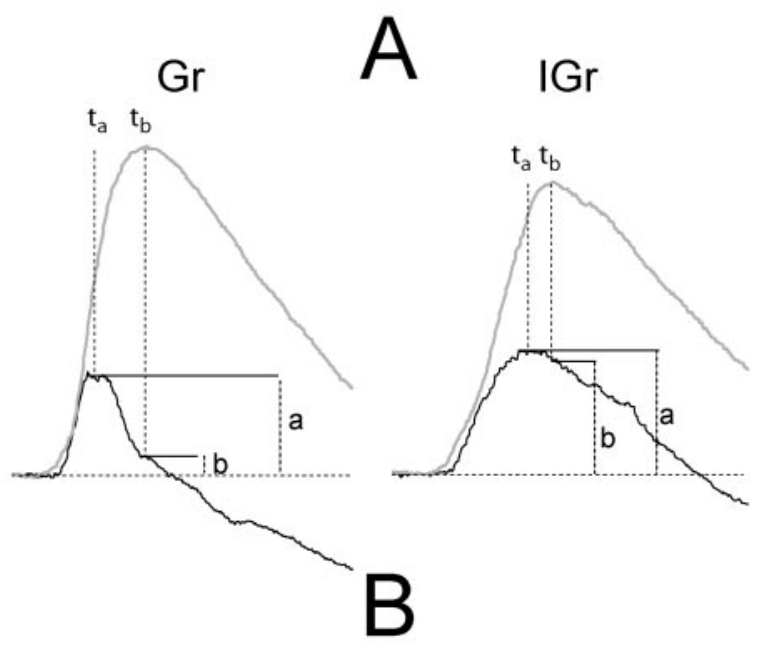

decrease in latency to peak $\%$ reduction in peak amplitude

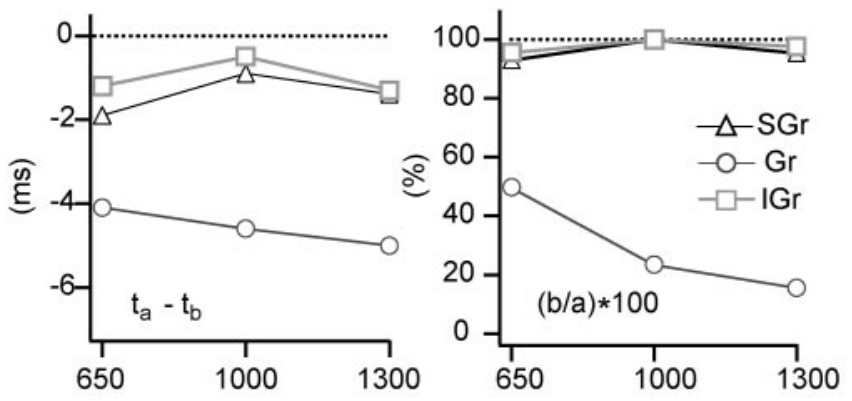

Figure 9. The effect of $V m$ on the shape of the population synaptic response. A, Population synaptic responses of $\mathrm{Gr}$ (left) and IGr (right) to the highest deflection velocity-acceleration at the depolarized and hyperpolarized Vms are shown in Figure 8 to illustrate where the measurements in the plots below were made. The dark trace is the response under depolarizing current, and the light trace is the response under hyperpolarization. SGr is not represented for simplicity. Letters indicate peak time of the depolarized response $\left(t_{\mathrm{a}}\right)$, peak time of the hyperpolarized response $\left(t_{b}\right)$, peak amplitude of the depolarized response (a), and amplitude of the depolarized response at the time of occurrence of the peak of the hyperpolarized response (measured by $t_{\mathrm{b}}$ ). B, Decrease in peak latency (left plot; $t_{\mathrm{a}}-t_{\mathrm{b}}$ ) caused by depolarization for the three highest deflection velocity-acceleration values. Reduction in peak amplitude (right plot), expressed as a percentage of amplitude of the peak of depolarized response $(b / a \cdot 100)$ is shown. Symbols represent the three population synaptic responses.

\section{Effect of stimulus intensity on the composition of the synaptic response}

To extend the findings illustrated in Figure 5 to the entire population, we applied the same procedures to the population synaptic responses (Fig. 8). Figure $8 \mathrm{~A}$ shows the population synaptic responses to the five velocities-accelerations at the resting $\mathrm{Vm}$, a hyperpolarized $\mathrm{Vm}$, and a depolarized $\mathrm{Vm}$. The traces were artificially offset to the same baseline to highlight the sequence of synaptic events. Changing deflection velocity-acceleration changed the latency and the amplitude but not the composition of the synaptic responses in each layer. For the highest velocityacceleration in $\mathrm{Gr}$ cells, depolarization above $-60 \mathrm{mV}$ reversed the polarity of most of the synaptic response with the exception of the first $10 \mathrm{msec}$. This reversal in polarity was consistent across all velocities and suggests that most of the synaptic response at rest is dominated by a reversed IPSP, most likely GABA $_{\mathrm{A}}$ mediated. In contrast, in SGr and IGr cells, depolarization resulted in much smaller reduction in the duration and amplitude of the synaptic response to all velocities and did not reverse its peak (Fig. 9). Common to the three population synaptic responses, increasing deflection velocity-acceleration increased the amplitude and de- 
creased the latency of the peak of the responses both under depolarization and hyperpolarization, suggesting that both the excitatory and inhibitory components increased in amplitude and decreased in latency.

In support of the conclusions derived from the observation of the current-clamp traces, the continuous plots of Rin showed that increasing deflection velocity-acceleration increased the amplitude of the drop in Rin from baseline and decreased the latency to its peak minimum. This suggests an increase in the magnitude and a decrease in the latency of the underlying synaptic input. The drop in Rin was larger in Gr cells and coincided with the peak of the response under hyperpolarization, probably reflecting the larger $\mathrm{GABA}_{\mathrm{A}}$ component in Gr cells, which dominates the Vm of Gr cells at that time. The continuous plots of Vrev further distinguished Gr cells from the other two populations. Vrev plots were not calculated for the two lowest velocities because the small response amplitude under depolarization made estimations unreliable. In response to the highest velocity-acceleration, the Gr population synaptic response showed an apparent Vrev peak of 0 $\mathrm{mV}$, which occurred $1.1 \mathrm{msec}$ before the peak of the short EPSP recorded under depolarization. The peak decreased in amplitude and duration with decreasing velocity-acceleration. The apparent Vrev plots of Gr cells converged to a short plateau (2-3 msec) at approximately $-60 \mathrm{mV}$, coinciding with the peak of the early IPSP and the peak minimum in Rin. Apparent Vrev values then decreased toward $-80 \mathrm{mV}$ with a time course similar to that of the late IPSP. In contrast, only for the highest velocity-acceleration did the population synaptic responses of SGr and IGr cells show a distinct peak in the Vrev plot, which reached a value of $-18 \mathrm{mV}$ for SGr and $-16 \mathrm{mV}$ for IGr cells. The peak was followed by a short plateau between -45 and $-40 \mathrm{mV}$. Apparent Vrev values for the next two lower velocities rose to the short plateau between -45 and $-40 \mathrm{mV}$ and did not show an early peak. The important point emphasized by the apparent Vrev plots is that in Gr cells, the Vrev of the response dropped below Vthr (Fig. 9, dotted line) after $5 \mathrm{msec}$ (for the three highest velocities), whereas it did so only after $\sim 16 \mathrm{msec}$ (for all three highest velocity-acceleration values) for SGr cells and after $\sim 16 \mathrm{msec}$ $(1300 \% \mathrm{sec}$ and $1000 \% \mathrm{sec}$ ) and $\sim 23 \mathrm{msec}$ (for $650 \% \mathrm{sec}$ ) for IGr cells. This suggests that, as discussed above in relationship to Figure 5, Gr cells have considerably shorter integration windows $(\sim 5-7 \mathrm{msec})$ before powerful inhibition clamps the Vm near the Vrev of $\mathrm{Cl}^{-}$. Thus, as velocity-acceleration increases, the response in Gr cells shows an increase in the amplitude and a decrease in latency of both the EPSP and the IPSP, in parallel with an increase in $\mathrm{dV} / \mathrm{dt}$. The immediate consequence of this process is the generation of responses with progressively higher temporal precision and reliability. In contrast, the longer time window in which the Vrev of the response of SGr and IGr cells stays above Vthr allows for a more prolonged integration of inputs.

The two most important distinguishing features among the population synaptic responses revealed by changing the Vm (illustrated in Fig. 8) were the change in the latency to the peak and the change in the shape of the response. These two values are quantified in Figure 9 for the three highest velocity-acceleration values, which produced more reliable measurements of the peak parameters because of their larger amplitude. To quantify the effect of $\mathrm{Vm}$ on the latency to the peak, we measured its value under depolarization (Fig. $9 A, t_{\mathrm{a}}$ ) and under hyperpolarization (Fig. $9 A, t_{\mathrm{b}}$ ) and subtracted the second from the first (Fig. $9 B$, left plot). The difference in latency caused by the change in $\mathrm{Vm}$ in the response to the three highest velocity-acceleration values was $>4$ msec in Gr cells and $<2$ msec in SGr and IGr cells. To quantify the

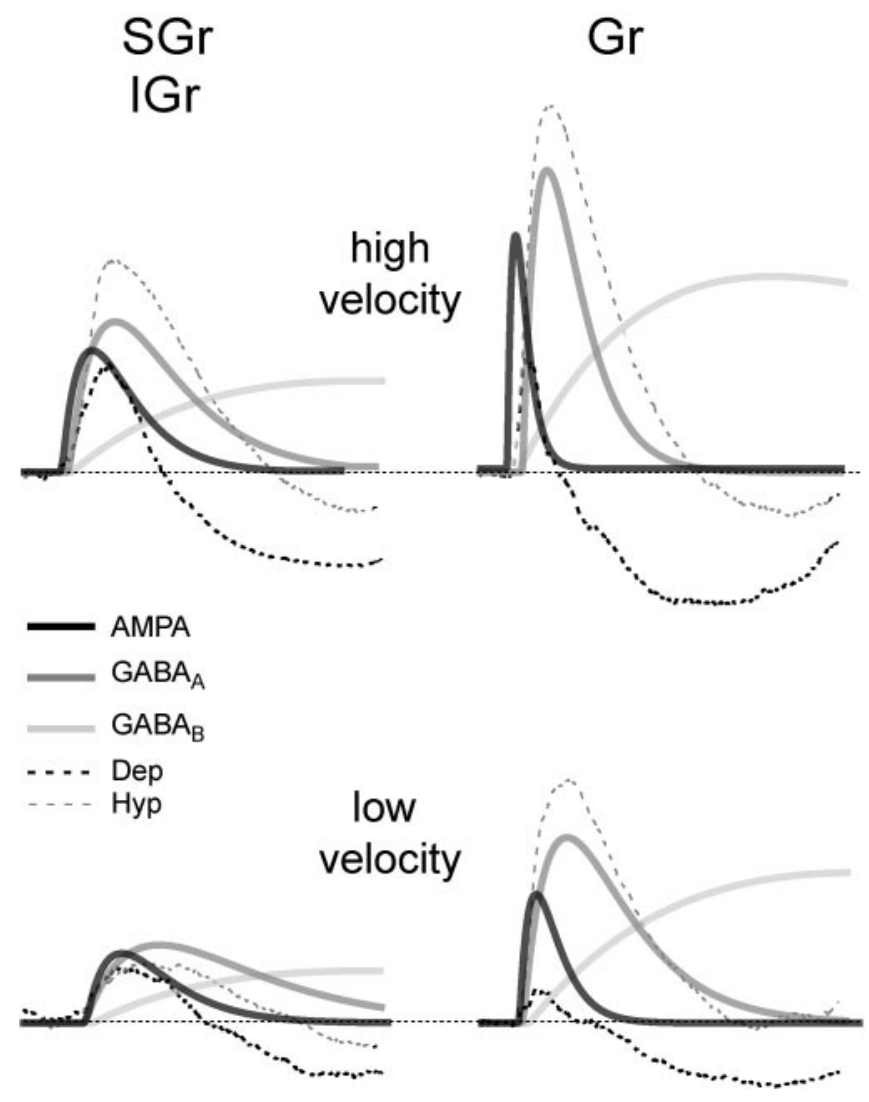

Figure 10. Schematic representation of the hypothetical arrangement of conductances underlying the synaptic responses. Excitatory, (AMPA, black) and inhibitory $\left(\mathrm{GABA}_{A}\right.$, dark gray; $\mathrm{GABA}_{\mathrm{B}}$, light gray) were drawn as $\alpha$ functions with an arbitrary amplitude and time constant. Conductances are represented superimposed on the population synaptic responses to the highest velocity-acceleration of SGr (left) and Gr (right) cells at a depolarized (Dep; black dotted) and hyperpolarized (Hyp; gray dotted) Vm. The left column is labeled SGr/IGr because, for purposes of this schematic, we considered the responses from these layers as equivalent in comparison with $\mathrm{Gr}$ layer. The population responses are the same shown in Figure 8 . We chose not to represent NMDA currents for simplicity (but see Feldmeyer et al., 1999). The three main points are as follows: (1) the time separation between AMPA and $\mathrm{GABA}_{\mathrm{A}}$ in Gr cells, which is enhanced in the response to the high velocity-acceleration (top right); (2) the amplitude of $\mathrm{GABA}_{\mathrm{A}}$ conductance, which is highest in $\mathrm{Gr}$ cells and dominates the response at all velocities once activated, and (3) the decrease in latency and increase in amplitude in all conductances with the increase in velocity-acceleration.

change in the shape of the response, we measured two values from the response under depolarization: (1) the amplitude at the peak (Fig. 9A, a), and (2) the amplitude at the time when the peak under hyperpolarization occurred (Fig. 9A, b). The effect of Vm on the response shape was quantified as the percentage ratio between the two values $(b / a \cdot 100)$ (Fig. 9B, right plot). In SGr and IGr cells, the amplitude of the EPSP under depolarization at the time of the peak under hyperpolarization was still at least $90 \%$ of the peak amplitude. In Gr cells, that value was 53\% for the response to $650 \% \mathrm{sec}, 22 \%$ to $1000 \% \mathrm{sec}$, and $18 \%$ in response to the highest velocity-acceleration $(1300 \% \mathrm{sec})$. Thus, depolarization dramatically affected the shape of the synaptic response in $\mathrm{Gr}$ cells but only slightly in IGr and SGr cells. The effect of Vm in the Gr cell response was, as discussed above, attributable to the presence of a strong early IPSP that followed the EPSP and was reversed by depolarization.

Finally, in Figure 10, we present a scheme summarizing our hypothesis about the conductances underlying the synaptic responses in different layers and to different input intensities. We 
collapsed SGr and IGr cells because their behavior is very similar for the purposes of the diagram. We used $\alpha$ functions with arbitrary time constants (between 1 and $20 \mathrm{msec}$ ) and amplitudes to represent the time course of the conductances. This function was chosen only for convenience, because the conductances we mean to represent result from the activation of not one but multiple synapses, which are probably located in different regions of the somatodendritic membrane with different degrees of electrotonic attenuation. The time course of conductance change is faster than that of the Vm because the PSP is the temporal integral of the input current (Barrett and Crill, 1974; Kapur et al., 1997). In brief, our results suggest that in Gr cells, the fast inhibitory conductance (Fig. 10, dark gray trace) $\left(\mathrm{GABA}_{\mathrm{A}}\right)$, once activated, is powerful enough to dominate the $\mathrm{Vm}$ at all velocity-acceleration values. Increasing deflection velocity-acceleration increases the amplitude and decreases the latency of both conductances; however, at the highest velocity-acceleration, a separation between the activation of the excitatory (Fig. 10, black trace) (AMPA) and inhibitory conductance becomes apparent, leading to the generation of an EPSP in the first 6-7 msec of the response. In contrast, in SGr and IGr cells, the inhibitory conductance is less powerful and does not dominate the response at any velocityacceleration. In SGr and IGr cells, excitatory and inhibitory conductances overlap in time for most of the response, and increasing deflection velocity-acceleration increases the amplitude and decreases the latency of both conductances, resulting in an EPSP that increases in amplitude over most of its duration.

\section{Discussion}

The aim of this study was to characterize the synaptic responses of barrel cortex neurons as a function of stimulus intensity and cortical depth. We varied stimulus intensity by increasing the PW deflection velocity-acceleration. The thrust was not to characterize synaptic responses as a function of either velocity or acceleration specifically, and we did not differentiate between these two variables of the ramp and hold stimuli. Instead, we wanted to determine how the composition of synaptic responses varies with stimulus intensity and cortical depth to gain insight into the input-output relationships of barrel cortex neurons located in different parts of the cortical microcircuit.

\section{Differences in synaptic and spike responses from different layers}

Our results show that there were significant differences in the EPSP at rest in response to the highest stimulus intensity between cells at different depths. The population synaptic response of IGr cells was delayed with respect to that of Gr cells and had the same onset latency as that of SGr cells. This is probably because of the fact that by collapsing layer 5 and 6 cells together (because of the similarity of their responses), we included cells with very different latencies to onset, ranging from 6.5 to $12.5 \mathrm{msec}$ (Fig. 2A, top left plot).

The sequence of activation of the layers shown here is in agreement with functional studies using intracortical field potential recordings and current source density analysis (Mitzdorf and Singer, 1979; Bode-Greuel et al., 1987; Di et al., 1990; Agmon and Connors, 1991; Kenan-Vaknin and Teyler, 1994; Lecas, 2004). Such studies have provided simple diagrams for the activation of cortex after thalamic input, in which early sinks in layers 4 and 6 are followed by activation of layers 3 and 2 and then layer 5 . These studies are supported by anatomical data showing the site of specific thalamic input to layers 4 and 6 (White, 1979; Herkenham, 1980; White and Hersch, 1982; Keller et al., 1985) and the projection patterns of pyramidal axons between cortical layers (for review, see Thomson and Bannister, 2003).

The difference in $\mathrm{dV} / \mathrm{dt}$ among layers may be attributable to differences in either the spatial distribution (i.e., the location with respect to the soma) or the temporal dispersion (i.e., the degree of synchronization) of their inputs. The first mechanism could play a role if layer 4 circuits are more compact than SGr or IGr circuits. However, the responses we recorded receive a large contribution of local circuit activity from different sources (Tarczy-Hornoch et al., 1999; Martin, 2002; Schubert et al., 2003) making predictions about the electrotonic distribution of the input very difficult. The second mechanism is supported in part by the highly synchronized input from thalamus to layer 4 at the highest velocity (Pinto et al., 2000), which has a high efficacy (Gil et al., 1999). This input also reaches layer 6 and could help increase the $\mathrm{dV} / \mathrm{dt}$ of IGr cells. In contrast, the dV/dt of SGr does not reflect the input from layer 4 , which is almost as brief $(7-8 \mathrm{msec})$ (Fig. 3 ) as its thalamic input (5-6 msec; Pinto et al., 2000). Therefore, other factors such as the rich reverberant excitatory and inhibitory activity of the local SGr network (Douglas and Martin, 1998; Martin, 2002; Thomson and Bannister, 2003) must contribute to the smaller $\mathrm{dV} / \mathrm{dt}$ and longer duration of the SGr synaptic response.

\section{Effect of increasing stimulus intensity on synaptic and spike responses at rest}

Our results show that in cells from all depths, increasing stimulus intensity increased the amplitude, increased the $\mathrm{dV} / \mathrm{dt}$, and decreased the latency to peak of the EPSP at rest. The changes in the EPSP were reflected in an increase in the spike output.

The simplest explanation for the behavior of the EPSP at rest as a function of stimulus intensity is to attribute it to the characteristics of the thalamic input. Recordings of multiunit activity from VB thalamus (Pinto et al., 2000) have shown that increasing the velocity-acceleration of whisker deflection primarily changes the time course of the thalamic response (i.e., progressively more spikes occur in the first few milliseconds with only a slight increase in the population response magnitude; expressed as total counts). In contrast, in layer 4 cortical neurons, the same study demonstrated that increasing velocity was primarily associated with an increase in the population response magnitude, similar to our increased spikes per stimulus.

In a related study, recordings of local field potentials (LFPs) from VB (Temereanca and Simons, 2003) demonstrated that increasing the velocity-acceleration of whisker deflection reduces the latency to onset, reduces the latency to peak, and increases the amplitude of the LFP response. These results are consistent with the multiunit recordings by Pinto et al. (2000) and are comparable with the synaptic responses of barrel cortex neurons shown here [compare Fig. $6 A$ in Temereanca and Simons (2003) with our Fig. 6].

Thus, the increase in the amplitude and the $\mathrm{dV} / \mathrm{dt}$ of the EPSP, which in turn leads to a decrease of the latency to peak, may result from the spatial and temporal summation of thalamic and cortical input, which increase with stimulus intensity. Spatial summation depends on the number and location of synaptic inputs, whereas temporal summation depends on the frequency of those inputs (Eccles, 1964; Hubbard et al., 1969; Johnston and $\mathrm{Wu}$, 1995). As velocity-acceleration increases, thalamic input increases and becomes more synchronized (Pinto et al., 1996), which in turn leads to an increase in local corticocortical activity. In addition, the increase in input frequency underlying temporal summation causes a decrease in the time constant of the postsyn- 
aptic target (Eccles, 1964; Hubbard et al., 1969; Johnston and Wu, 1995), which results in a faster rate of rise of the EPSP.

The linear increase in $\mathrm{dV} / \mathrm{dt}$ with velocity suggests that the synaptic input grew linearly with velocity, and there was no visible contribution to the response of membrane nonlinearities caused by intrinsic electrophysiological properties (Llinas, 1988). This is also in agreement with the linear $V-I$ plots presented here. Finally, the duration of the EPSP changed little with the increase in stimulus intensity, which is in agreement with the small change in duration of the cortical population PSTHs reported by Pinto et al. (2000).

\section{Composition of the synaptic responses}

Elucidating the nature of synaptic inputs to individual cells within a layer provides critical information regarding the organization and dynamics of the local cortical network. Our results are based on current-clamp recordings presumably obtained at the soma and therefore, we cannot determine whether depolarization or hyperpolarization changes the propagation of synaptic currents along the dendrite or the value of Vrev at the site of the synaptic input. This information can only be obtained by wholecell recordings from dendrites (Reyes, 2001). Our results show that the synaptic response of Gr cells was composed of a short EPSP, followed by a powerful early IPSP that truncated the EPSP at depolarized Vms [as also shown by Istvan and Zarzecki (1994) and by Moore and Nelson (1998)] and then by a late IPSP. In IGr and SGr cells, a dominant early IPSP was absent, and the EPSP was longer lasting and then followed by a late IPSP.

The observation of the current-clamp traces supported by the values of apparent Vrev and Rin strongly suggest that there are two main differences between the synaptic response of $\mathrm{Gr}$ and non-Gr cells: (1) the time course of activation of the underlying conductances, and (2) the amplitude of the inhibitory conductance (see scheme in Fig. 10).

For SGr and IGr cells, changing the Vm had little effect on the shape of the EPSP (Fig. 9). The corresponding drop in Rin and values of apparent Vrev suggested that the EPSP resulted from a combination of excitatory and inhibitory conductances. More importantly, the apparent Vrev was above Vthr for most of the response and was associated with a small drop in Rin, which together favor the integration of additional inputs to increase spike output. In contrast, for Gr cells, changing the Vm dramatically affected the shape of the EPSP (Fig. 9) (Istvan and Zarzecki, 1994; Moore and Nelson, 1998; Zhu and Connors, 1999). Depolarization revealed that most of the response at rest was in fact a reversed IPSP. Indeed, the Vrev of the response after the first 6-8 msec was below Vthr, which together with the large drop in Rin caused summation of inputs past the duration of the early EPSP extremely unlikely.

\section{Conclusion}

Our data fully support the hypothesis of Pinto et al. (2000), which proposes that barrel neurons (layer 4) are particularly sensitive to the temporal distribution of thalamic input, because only initially synchronous inputs can generate an excitatory response before it is suppressed by the strong local inhibition in layer 4 . In addition, our data suggest that different rules apply to supragranular and infragranular circuits, where local inhibition does not seem as strong and is coactivated with excitation during the generation of suprathreshold EPSPs. Such differences in the timing and strength of local inhibition suggest that, whereas layer 4 is designed to filter out asynchronous inputs and perform coinci- dence detection, supragranular and infragranular circuits are better designed to integrate their inputs over time.

\section{References}

Agmon A, Connors BW (1991) Thalamocortical responses of mouse somatosensory (barrel) cortex in vitro. Neuroscience 41:365-379.

Anderson JS, Carandini M, Ferster D (2000) Orientation tuning of input conductance, excitation, and inhibition in cat primary visual cortex. J Neurophysiol 84:909-926.

Anderson JS, Lampl I, Gillespie DC, Ferster D (2001) Membrane potential and conductance changes underlying length tuning of cells in cat primary visual cortex. J Neurosci 21:2104-2112.

Barrett JN, Crill WE (1974) Influence of dendritic location and membrane properties on the effectiveness of synapses on cat motoneurones. J Physiol (Lond) 239:325-345.

Berg RW, Kleinfeld D (2003) Rhythmic whisking by rat: retraction as well as protraction of the vibrissae is under active muscular control. J Neurophysiol 89:104-117.

Bermejo R, Houben D, Zeigler HP (1998) Optoelectronic monitoring of individual whisker movements in rats. J Neurosci Methods 83:89-96.

Bode-Greuel KM, Singer W, Aldenhoff JB (1987) A current source density analysis of field potentials evoked in slices of visual cortex. Exp Brain Res 69:213-219.

Brecht M, Sakmann B (2002) Dynamic representation of whisker deflection by synaptic potentials in spiny stellate and pyramidal cells in the barrels and septa of layer 4 rat somatosensory cortex. J Physiol (Lond) 543:49-70.

Brecht M, Roth A, Sakmann B (2003) Dynamic receptive fields of reconstructed pyramidal cells in layers 3 and 2 of rat somatosensory cortex. J Physiol (Lond) 553:243-265.

Carvell GE, Simons DJ (1990) Biometric analyses of vibrissal tactile discrimination in the rat. J Neurosci 10:2638-2648.

Carvell GE, Simons DJ (1995) Task- and subject-related differences in sensorimotor behavior during active touch. Somatosens Mot Res 12:1-9.

Cowan NJ, Ma EJ, Cutkosky M, Full RJ (2004) A biologically inspired passive antenna for steering control of a running robot. In: International symposium on robotics research. Siena, Italy: Springer.

Deschenes M, Timofeeva E, Lavallee P (2003) The relay of high-frequency sensory signals in the Whisker-to-barreloid pathway. J Neurosci 23:6778-6787.

Di S, Baumgartner C, Barth DS (1990) Laminar analysis of extracellular field potentials in rat vibrissa/barrel cortex. J Neurophysiol 63:832-840.

Douglas R, Martin KA (1998) Neocortex. In: The synaptic organization of the brain (Shepherd G, ed), pp 459-509. New York: Oxford UP.

Dykes RW (1975) Afferent fibers from mystacial vibrissae of cats and seals. J Neurophysiol 38:650-662.

Eccles J (1964) The physiology of synapses. Berlin: Springer.

Feldmeyer D, Egger V, Lubke J, Sakmann B (1999) Reliable synaptic connections between pairs of excitatory layer 4 neurones within a single "barrel" of developing rat somatosensory cortex. J Physiol (Lond) 521:169-190.

Gibson JM, Welker WI (1983) Quantitative studies of stimulus coding in first-order vibrissa afferents of rats. II. Adaptation and coding of stimulus parameters. Somatosens Res 1:95-117.

Gil Z, Connors BW, Amitai Y (1999) Efficacy of thalamocortical and intracortical synaptic connections: quanta, innervation, and reliability. Neuron 23:385-397.

Guic-Robles E, Valdivieso C, Guajardo G (1989) Rats can learn a roughness discrimination using only their vibrissal system. Behav Brain Res 31:285-289.

Herkenham M (1980) Laminar organization of thalamic projections to the rat neocortex. Science 207:532-535.

Higley MJ, Contreras D (2003) Nonlinear integration of sensory responses in the rat barrel cortex: an intracellular study in vivo. J Neurosci 23:10190-10200.

Hubbard JI, Llinas R, Quatel DMJ (1969) Electrophysiological analysis of synaptic transmission. Baltimore: Williams and Wilkins.

Hubel DH, Wiesel TN (1962) Receptive fields, binocular interaction and functional architecture in the cat's visual cortex. J Physiol (Lond) 160:106-154

Istvan PJ, Zarzecki P (1994) Intrinsic discharge patterns and somatosensory inputs for neurons in raccoon primary somatosensory cortex. J Neurophysiol 72:2827-2839. 
Ito M (1985) Processing of vibrissa sensory information within the rat neocortex. J Neurophysiol 54:479-490.

Ito M (1992) Simultaneous visualization of cortical barrels and horseradish peroxidase-injected layer $5 \mathrm{~b}$ vibrissa neurones in the rat. J Physiol (Lond) 454:247-265.

Johnston D, Wu SM (1995) Foundations of cellular neurophysiology. Cambridge, MA: MIT.

Kapur A, Pearce RA, Lytton WW, Haberly LB (1997) GABAA-mediated IPSCs in piriform cortex have fast and slow components with different properties and locations on pyramidal cells. J Neurophysiol 78: 2531-2545.

Keller A, White EL, Cipolloni PB (1985) The identification of thalamocortical axon terminals in barrels of mouse Sml cortex using immunohistochemistry of anterogradely transported lectin (Phaseolus vulgarisleucoagglutinin). Brain Res 343:159-165.

Kenan-Vaknin G, Teyler TJ (1994) Laminar pattern of synaptic activity in rat primary visual cortex: comparison of in vivo and in vitro studies employing the current source density analysis. Brain Res 635:37-48.

Lecas J (2004) Locus coeruleus activation shortens synaptic drive and improves spike latency and spike timing in sensorimotor cortex. Implications for neuronal integration. Eur J Neurosci, in press.

Lee SH, Simons DJ (2004) Angular tuning and velocity sensitivity in different neuron classes within layer 4 of rat barrel cortex. J Neurophysiol 91:223-229.

Lichtenstein SH, Carvell GE, Simons DJ (1990) Responses of rat trigeminal ganglion neurons to movements of vibrissae in different directions. Somatosens Mot Res 7:47-65.

Llinas RR (1988) The intrinsic electrophysiological properties of mammalian neurons: insights into central nervous system function. Science 242:1654-1664.

Martin KA (2002) Microcircuits in visual cortex. Curr Opin Neurobiol $12: 418-425$.

Mitzdorf U, Singer W (1979) Excitatory synaptic ensemble properties in the visual cortex of the macaque monkey: a current source density analysis of electrically evoked potentials. J Comp Neurol 187:71-83.

Monier C, Chavane F, Baudot P, Graham LJ, Fregnac Y (2003) Orientation and direction selectivity of synaptic inputs in visual cortical neurons: a diversity of combinations produces spike tuning. Neuron 37:663-680.

Moore CI, Nelson SB (1998) Spatio-temporal subthreshold receptive fields in the vibrissa representation of rat primary somatosensory cortex. J Neurophysiol 80:2882-2892.

Moore CI, Nelson SB, Sur M (1999) Dynamics of neuronal processing in rat somatosensory cortex. Trends Neurosci 22:513-520.
Mountcastle VB (1957) Modality and topographic properties of single neurons of cat's somatic sensory cortex. J Neurophysiol 20:408-434.

Pinto DJ, Brumberg JC, Simons DJ, Ermentrout GB (1996) A quantitative population model of whisker barrels: re-examining the Wilson-Cowan equations. J Comput Neurosci 3:247-264.

Pinto DJ, Brumberg JC, Simons DJ (2000) Circuit dynamics and coding strategies in rodent somatosensory cortex. J Neurophysiol 83:1158-1166.

Pinto DJ, Hartings JA, Brumberg JC, Simons DJ (2003) Cortical damping: analysis of thalamocortical response transformations in rodent barrel cortex. Cereb Cortex 13:33-44.

Reyes A (2001) Influence of dendritic conductances on the input-output properties of neurons. Annu Rev Neurosci 24:653-675.

Schubert D, Kotter R, Zilles K, Luhmann HJ, Staiger JF (2003) Cell type-specific circuits of cortical layer IV spiny neurons. J Neurosci 23:2961-2970.

Shoykhet M, Doherty D, Simons DJ (2000) Coding of deflection velocity and amplitude by whisker primary afferent neurons: implications for higher level processing. Somatosens Mot Res 17:171-180.

Simons DJ (1978) Response properties of vibrissa units in rat SI somatosensory neocortex. J Neurophysiol 41:798-820.

Simons DJ (1983) Multiwhisker stimulation and its effects on vibrissae units in rat SMI barrel cortex. Brain Res 276:178-182.

Tarczy-Hornoch K, Martin KA, Stratford KJ, Jack JJ (1999) Intracortical excitation of spiny neurons in layer 4 of cat striate cortex in vitro. Cereb Cortex 9:833-843.

Temereanca S, Simons DJ (2003) Local field potentials and the encoding of whisker deflections by population firing synchrony in thalamic barreloids. J Neurophysiol 89:2137-2145.

Thomson AM, Bannister AP (2003) Interlaminar connections in the neocortex. Cereb Cortex 13:5-14.

Welker WI, Johnson Jr JI, Pubols Jr BH (1964) Some morphological and physiological characteristics of the somatic sensory system in raccoons. Am Zool 136:75-94.

White EL (1979) Thalamocortical synaptic relations: a review with emphasis on the projections of specific thalamic nuclei to the primary sensory areas of the neocortex. Brain Res 180:275-311.

White EL, Hersch SM (1982) A quantitative study of thalamocortical and other synapses involving the apical dendrites of corticothalamic projection cells in mouse SmI cortex. J Neurocytol 11:137-157.

Wong-Riley M (1979) Changes in the visual system of monocularly sutured or enucleated cats demonstrable with cytochrome oxidase histochemistry. Brain Res 171:11-28.

Zhu JJ, Connors BW (1999) Intrinsic firing patterns and whisker-evoked synaptic responses of neurons in the rat barrel cortex. J Neurophysiol 81:1171-1183. 